\title{
¿LA NOCIÓN DE «PAÍS SEGURO»ES SEGURA? \\ UN ANÁLISIS A LA LUZ DE LA JURISPRUDENCIA \\ DEL TRIBUNAL EUROPEO DE DERECHOS HUMANOS
}

\author{
CAROLINA SOLER GARCÍA ${ }^{1}$ \\ Universidad de Alicante \\ carolina.soler@ua.es
}

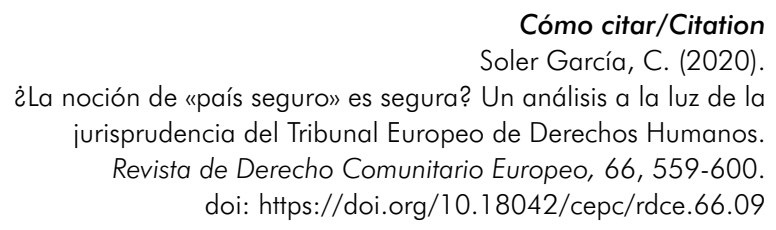

Resumen

La Directiva 2013/32/UE contempla tres nociones de país seguro. En primer lugar, la aplicación de la noción de "país de origen seguro» permite al Estado miembro la tramitación de una solicitud de protección internacional de un nacional de ese país a través de un procedimiento acelerado. En segundo lugar, la aplicación de la noción de "tercer país seguro" posibilita que el Estado miembro inadmita una solicitud de protección internacional. Y en tercer lugar, la aplicación de la noción de «tercer país seguro europeo" permite que el Estado miembro no realice, o al menos que no lo haga de forma completa, el examen de la solicitud de protección internacional. Algunos Estados miembros han adoptado listas nacionales de países de origen seguros, e incluso la Comisión ha propuesto que se adopte una lista común europea de países de

1 Profesora ayudante doctora (acreditada a contratada doctora) de Derecho Internacional Público y Relaciones Internacionales de la Universidad de Alicante. Este trabajo se ha elaborado en el marco de las actividades de investigación que se desarrollan en la Cátedra Jean Monnet «European Neighbourhood Policy: EU Values and Global Challenges» (599477-EPP-1-2018-ES-EPPJMO-CHAIR). La autora agradece las observaciones que los dos evaluadores llevaron a cabo sobre este trabajo. 
origen seguros. En todo caso, tanto la práctica convencional, legislativa, administrativa y judicial de los Estados miembros como la aplicación de los acuerdos de readmisión suscritos por la UE deben cumplir con lo dispuesto en la Directiva 2013/32/UE, el CEDH y la jurisprudencia del TEDH. El estudio de la jurisprudencia del TEDH que interpreta y aplica los arts. 2 y 3 del CEDH demuestra la necesidad de realizar un examen completo y ex nunc tanto de las circunstancias imperantes en un determinado Estado como de las circunstancias concretas de la persona objeto de expulsión, antes de proceder a su expulsión. De lo contrario, el establecimiento de una lista atemporal y despersonalizada de países de origen seguros puede colisionar con la jurisprudencia del TEDH. En este sentido, la jurisprudencia de este Tribunal arroja criterios que permiten desarrollar los establecidos en la Directiva 2013/32/UE, con el fin de que la catalogación de un país como seguro descanse en el efectivo respeto de los derechos humanos, uno de los valores sobre los que se fundamenta la UE.

\title{
Palabras clave
}

Directiva de Procedimiento; país seguro; solicitantes de protección internacional; expulsión; Convenio Europeo de Derechos Humanos; Tribunal Europeo de Derechos Humanos.

\section{IS THE CONCEPT OF A "SAFE COUNTRY" SAFE? AN ANALYSIS IN THE LIGHT OF THE JURISPRUDENCE OF THE EUROPEAN COURT OF HUMAN RIGHTS}

\begin{abstract}
The Directive 2013/32/EU contemplates three concepts of safe country. First, the application of the concept of "safe country of origin" allows the Member State to process an application for international protection by a national of that country through an accelerated procedure. Second, the application of the concept of "safe third country" makes it possible for the Member State to reject an application for international protection. And third, the application of the concept of "European safe third" country allows the Member State not to carry out, or at least not to do so completely, the examination of the application for international protection. Some Member States have adopted national lists of safe countries of origin, and even the Commission has proposed that a common European list of safe countries of origin be adopted. In any case, both the legislative, administrative and judicial practice of the Member States, as well as the application of readmission agreements signed by the EU, must comply with Directive 2013/32/EU, the ECHR and the ECHR jurisprudence. The study of the ECHR jurisprudence that interprets and applies Arts. 2 and 3 of the ECHR, demonstrates the need for a complete and ex nunc examination of both the prevailing circumstances in a given State and the specific circumstances of the person subject to expulsion, before proceeding with
\end{abstract}


the expulsion. Otherwise, the establishment of a timeless and depersonalized list of safe countries of origin can come into conflict with the ECtHR jurisprudence. In this regard, the jurisprudence of this Court provides criteria that allow the development of those set out in Directive 2013/32/EU, in order that the classification of a country as safe is based on the effective respect of human rights, one of the values on which the EU is founded.

\section{Keywords}

Procedure Directive; safe country; applicants for international protection; expulsion; European Convention on Human Rights; European Court of Human Rights.

\section{LE CONCEPT DE «PAYS SÛR» EST-IL SÛR? UNE ANALYSE À LA LUMIÈRE DE LA JURISPRUDENCE DE LA COUR EUROPÉENNE DES DROITS DE L'HOMME}

\section{Résumé}

La Directive 2013/32/UE envisage trois concepts de pays sûr. Premièrement, l'application du concept de "pays d'origine sûr» permet à l'État membre de traiter une demande de protection internationale par un ressortissant de ce pays par le biais d'une procédure accélérée. Deuxièmement, l'application du concept de "pays tiers sûr» permet à l'État membre de rejeter une demande de protection internationale. Et troisièmement, l'application du concept de "pays tiers européen» sûr permet à l'État membre de ne pas procéder, ou du moins de ne pas le faire complètement, à l'examen de la demande de protection internationale. Certains États membres ont adopté des listes nationales de pays d'origine sûrs, et même la Commission a proposé qu'une liste européenne commune des pays d'origine sûrs soit adoptée. En tout cas, la pratique législative, administrative et judiciaire des États membres, ainsi que l'application des accords de réadmission signés par l'UE, doivent être conformes à la Directive 2013/32/UE, à la CEDH et à la jurisprudence de la CEDH. L'étude de la jurisprudence de la $\mathrm{CEDH}$ qui interprète et applique les arts. 2 et 3 de la $\mathrm{CEDH}$, démontre la nécessité d'un examen complet et ex nunc à la fois des circonstances prévalant dans un État donné et des circonstances spécifiques de la personne en cours d'expulsion, avant de procéder à son expulsion. Sinon, l'établissement d'une liste intemporelle et dépersonnalisée des pays d'origine sûrs pourrait entrer en conflit avec la jurisprudence de la CEDH. En ce sens, la jurisprudence de cette Cour énonce des critères qui permettent le développement de ceux établis dans la Directive 2013/32/UE, de sorte que la classification d'un pays comme sûr repose sur le respect effectif des droits de l'homme, l'un des valeurs sur lesquelles l'UE est fondée.

\section{Mots clés}

Directive sur la procédure; pays sûr; demandeurs de protection internationale; l'expulsion; Convention européenne des droits de l'homme; Cour européenne des droits de l'homme. 


\section{SUMARIO}

I. INTRODUCCIÓN. II. LA NOCIÓN DE PAÍS SEGURO EN LA NORMATIVA DE LA UNIÓNEUROPEA. III. LAAPLICACIÓNDELANOCIÓNDE PAIIS SEGUROENLAUNIÓN EUROPEA: 1. La práctica convencional. 2. La propuesta de la Comisión Europea por la que se establece una lista común enuropea de países de origen seguros. IV. LA PRÁCTICA DE LOS ESTADOS MIEMBROS DE LA UNIÓN EUROPEA RELACIONADA CON LA NOCIÓN DE PAÍS SEGURO. V. LA JURISPRUDENCIA DEL TEDH SOBRE LA SITUACIÓN EN EL ESTADO DE DESTINO Y LOS FACTORES RATIONE PERSONAE: 1. La situación general de derechos humanos en el Estado de destino. 2. Los factores ratione personae. VI. LAS GARANTÍAS ASOCIADAS AL CONCEPTO DE TERCER ESTADO SEGURO A EFECTOS DE EXPULSIÓN SEGÚN EL TEDH: 1. El respeto del art. 3 del CEDH: la prohibición de non refoulement indirecto. 2. El respeto a la vida: la prohibición de la pena de muerte. VII. LA JURISPRUDENCIA DEL TEDH APLICADA A LOS ESTADOS MIEMBROS DE LA UE. VIII. CONSIDERACIONES FINALES. BIBLIOGRAFIA.

\section{INTRODUCCIÓN}

En los últimos años los Estados europeos están tratando de gestionar la crisis migratoria también desde una dimensión externa. Una de las medidas adoptadas para controlar la inmigración consiste en hacer recaer en terceros Estados la tarea de tramitar las solicitudes de asilo. Así, «el país en el que de facto se halla el solicitante elude la decisión sobre el fondo y la traslada a otro país que presupone que es un país seguro para el solicitante. Por tanto, este tercer país tiene la responsabilidad principal de examinar su solicitud e incluso de acogerlo» (Abrisketa Uriarte, 2019: 212).

En el ámbito del derecho de la UE, la noción de país seguro se encuentra regulada en la Directiva 2013/32/UE ${ }^{2}$ (en adelante, Directiva de Procedimiento). En concreto establece tres acepciones de país seguro: país de origen seguro (art. 36) tercer país seguro (art. 38) y país seguro europeo (art. 39). Como se explica en el epígrafe II, la aplicación de estas tres nociones permite a los Estados miembros, respectivamente, disponer de un procedimiento acelerado

2 Directiva 2013/32/UE del Parlamento Europeo y del Consejo de 26 de junio de 2013 sobre procedimientos comunes para la concesión o la retirada de la protección internacional (refundición) (DO L 180/60, de 29 de junio de 2013). 
de tramitación de una solicitud de protección internacional; considerar esta inadmisible y enviar al solicitante de asilo al tercer país seguro donde podrá pedir protección internacional; y no realizar o no realizar completamente un examen de la solicitud. En los epígrafes III y IV, se dará cuenta de algunos desarrollos de la práctica de la UE y de sus Estados miembros en la aplicación del concepto de país seguro. Dadas las limitaciones de extensión de este trabajo, no es posible realizar un análisis exhaustivo de la práctica de la UE y de sus Estados miembros en la aplicación del concepto "país seguro", sin perjuicio de que se dedique una especial atención, por una parte, a la práctica de la UE con relación a Turquía, y, por otra, a la práctica de España, en particular en sus relaciones con Marruecos. Se ha considerado que en ambos casos la importancia de las relaciones de cooperación en materia migratoria con estos dos Estados justifica sobradamente esta selección en el estudio de la práctica.

Además, como se va a demostrar a continuación, la aplicación de las mencionadas tres acepciones que se recogen en la Directiva de Procedimiento debe ser conforme con la jurisprudencia del Tribunal Europeo de Derechos Humanos (TEDH), que interpreta y aplica las disposiciones del CEDH; en concreto, la relativa a los arts. 2 - derecho a la vida - y 3 - prohibición de la tortura-. El incremento de los flujos migratorios ha ido acompañado de un notable crecimiento del número de sentencias del TEDH sobre la compatibilidad de las obligaciones de los Estados parte en materia de protección de los derechos humanos y la aplicación que llevan a cabo del sistema de asilo (Panella, 2018: 276). Desde luego, la creciente afluencia de solicitantes de protección internacional no exime a los Estados parte de cumplir tales preceptos, que son inderogables ${ }^{3}$.

En este sentido, la jurisprudencia del TEDH contribuye a perfilar la noción de país seguro al establecer criterios interpretativos que permiten concretar si la expulsión de un solicitante de protección internacional respeta sus derechos humanos, siempre según el CEDH. El TEDH lleva a cabo un análisis tanto a la luz del panorama sobre el cumplimiento de los derechos humanos en el Estado (V.1) como de conformidad con los factores ratione personae (V.2). El TEDH, a partir de la interpretación y aplicación de los arts. 2 y 3, desarrolla una jurisprudencia en torno a la prohibición de non refoulement indirecto y la protección del derecho a la vida (VI). Asimismo, los Estados miembros deben tener en cuenta la jurisprudencia del TEDH a la hora de proceder al traslado de extranjeros entre Estados miembros de la UE (VII).

3 Sentencia del TEDH de 21 de enero de 2011, M.S.S. v. Belgium and Greece, CE: ECHR:2011:0121JUD003069609, párr. 223; Sentencia del TEDH de 14 de marzo de 2017, Ilias and Ahmed v. Hungary, CE:ECHR:2017:0314JUD004728715, párr. 83. 
Por último, el TEDH ha desarrollado una jurisprudencia en torno a las garantías diplomáticas a partir de la interpretación y aplicación del art. 3 del CEDH. Esta jurisprudencia ha permitido concretar unos criterios interpretativos generales que permiten valorar la seguridad de un país para una determinada persona en un momento dado. En el contexto de la valoración de la práctica protagonizada por la UE y sus Estados miembros a la luz de la jurisprudencia del TEDH, cabe propugnar que se tengan en cuenta algunos de estos criterios para desarrollar los principios establecidos en la Directiva de Procedimiento para aplicar la noción de país seguro, a fin de que la expulsión de un extranjero descanse en una efectiva protección de los derechos humanos (VIII).

\section{LA NOCIÓN DE PAÍS SEGURO EN LA NORMATIVA DE LA UNIÓN EUROPEA}

La Directiva de Procedimiento es uno de los cinco instrumentos legislativos que componen el Sistema Europeo Común de Asilo (SECA) ${ }^{4}$. Su propósito es establecer normas mínimas para los procedimientos que deben aplicar los Estados miembros a la hora de conceder o retirar el estatuto de protección internacional. Para ello, según se explicaba en la propuesta de Directiva de Procedimiento, las medidas contempladas en esta norma tratarían de mejorar la coherencia entre los instrumentos de asilo de la UE, simplificar, racionalizar y

\footnotetext{
Los otros cuatro actos legislativos son: la Directiva de Reconocimiento [(Directiva 2011/95/UE de Parlamento Europeo y del Consejo de 13 de diciembre de 2011 por la que se establecen normas relativas a los requisitos para el reconocimiento de nacionales de terceros países o apátridas como beneficiarios de protección internacional, a un estatuto uniforme para los refugiados o para las personas con derecho a protección subsidiaria y al contenido de la protección concedida (refundición) (DO L 337/9, de 13 de diciembre de 2011)]; el Reglamento Eurodac [Reglamento (UE) No 603/2013 del Parlamento Europeo y del Consejo de 26 de junio de 2013 relativo a la creación del sistema «Eurodac» (refundición) (DO L 180/1, de 29 de junio de 2013)]; el Reglamento Dublín [Reglamento (UE) No 604/2013 del Parlamento Europeo y del Consejo de 26 de junio de 2013 por el que se establecen los criterios y mecanismos de determinación del Estado miembro responsable del examen de una solicitud de protección internacional presentada en uno de los Estados miembros por un nacional de un tercer país o un apátrida (Texto refundido) (DO L 180/31, de 29 de junio de 2013)]; y la Directiva sobre las condiciones de acogida [Directiva 2013/33/UE del Parlamento Europeo y del Consejo de 26 de junio de 2013 por la que se aprueban normas para la acogida de los solicitantes de protección internacional (texto refundido) (DO L 180/96, de 29 de junio de 2013)].
} 
consolidar los requisitos procedimentales en todo el territorio de la Unión, con el fin de mejorar la eficiencia del procedimiento de asilo5. Por tanto, como se establece en los considerandos, el objetivo principal de esta norma es establecer un procedimiento común de asilo en la Unión. El fin último es contribuir a limitar los movimientos secundarios de los solicitantes de protección internacional entre Estados miembros cuanto tales movimientos vengan causados por las diferencias entre los marcos jurídicos.

Para conseguir estos objetivos, entre otras medidas, la Directiva de Procedimiento desarrolla tres nociones: la noción de país de origen seguro (art. 36); la noción de tercer país seguro (art. 38); y la noción de tercer país seguro europeo (art. 39).

En primer lugar, esta norma establece que un país es un país de origen seguro cuando, de conformidad con el anexo I de la Directiva de Procedimiento, pueda demostrarse que, de manera general y sistemática, no existen persecución, tortura o tratos o penas inhumanos o degradantes ni amenaza de violencia indiscriminada en situaciones de conflicto armado internacional o interno. Un país designado como país de origen seguro podrá considerarse como tal para un solicitante si, tras un examen individual de la solicitud: «a) el solicitante posee la nacionalidad de dicho país, o; b) es apátrida y anteriormente tuvo su residencia habitual en dicho país, y no ha aducido motivo grave alguno para que el país no se considere país de origen seguro en sus circunstancias particulares a los efectos de su derecho a ser beneficiario de protección internacional de conformidad con la Directiva 2011/95/UE» (art. 36).

La aplicación de esta noción permite a los Estados miembros tramitar una solicitud de protección internacional de un nacional de un país seguro, mediante un procedimiento acelerado o que el mismo se lleve a cabo en la frontera o en zonas de tránsito de conformidad con el art. 43 de la Directiva de Procedimiento (art. 31.8, letra b). A la hora de referirse al procedimiento acelerado, la directiva se remite al derecho nacional, concediendo una gran discrecionalidad a los Estados miembros en la regulación normativa de dicho procedimiento acelerado. La única referencia que hace la directiva acerca de los requisitos que deben cumplir los procedimientos acelerados se encuentra en el considerando 20 de esta norma ${ }^{6}$.

5 Propuesta de Directiva del Parlamento Europeo y del Consejo sobre normas mínimas para los procedimientos que deben aplicar los Estados miembros para conceder o retirar la protección internacional (refundición) \{SEC (2009) 1376\} \{SEC (2009) 1377\}, Bruselas, 21 de octubre de 2009, COM(2009) 554 final, 2009/0165 (COD).

6 El considerando 20 establece que los procedimientos acelerados, aunque deben establecer plazos más breves, estos deben ser razonables, sin perjuicio de un examen 
Además, el art. 37 establece la posibilidad de que los Estados miembros prevean en su legislación interna el establecimiento de listas de países de origen seguros, de conformidad con lo dispuesto en el anexo I de la directiva. En estos casos, es el solicitante quien debe demostrar que su país de origen no es seguro por algún «motivo grave», según lo dispuesto en la ya citada Directiva 2011/95/UE. Por tanto, la carga de la prueba recae sobre el solicitante, quien debe probar el temor fundado de persecución o riesgo grave $y$, además, demostrar que su país de procedencia no es seguro para él debido a las circunstancias particulares que tendrá que demostrar.

En segundo lugar, la noción de tercer país seguro permite a los Estados miembros considerar inadmisible la solicitud de protección internacional de aquellos que provengan de un país catalogado en este sentido (art. 33.2, letra c). Los Estados miembros solo podrán aplicar este concepto cuando las autoridades competentes tengan la certeza de que el solicitante de protección internacional recibirá en el tercer país un trato conforme a los siguientes principios:

— su vida o su libertad no están amenazadas por razón de raza, religión, nacionalidad, pertenencia a un grupo social particular u opinión política.

- no hay riesgo de daños graves tal como se definen en la Directiva 2011/95/UE.

- se respeta el principio de no devolución de conformidad con la Convención de Ginebra.

- se respeta la prohibición de expulsión en caso de violación del derecho de no ser sometido a torturas ni a tratos crueles, inhumanos o degradantes, establecido en el derecho internacional.

- existe la posibilidad de solicitar el estatuto de refugiado y, en caso de ser refugiado, recibir protección con arreglo a la Convención de Ginebra $(\text { art. 38.1) })^{7}$.

En este caso, los solicitantes de protección internacional no son nacionales ni apátridas con residencia habitual en tal país. Si bien, el Estado miembro traslada la responsabilidad del examen de su solicitud de protección

adecuado y completo de la solicitud que salvaguarde las garantías fundamentales establecidas en la Directiva de Procedimiento.

7 La ratificación de la Convención de 1951 y su Protocolo adicional es relevante para catalogar a un tercer país como seguro; sin embargo, no es preceptivo. El requisito central es que el Estado receptor permita a los solicitantes recibir los derechos previstos en la Convención de Ginebra (Binkovitz, 2018: 609). 
internacional a este tercer país seguro donde, de conformidad con la directiva, pueden solicitar asilo, y donde su vida, su integridad física y el principio de no devolución no se verán menoscabados. Además, este concepto también se integra en el SECA a través del Reglamento Dublín III, cuyo art. 3.3 permite a los Estados miembros la posibilidad de trasladar a un solicitante de protección internacional a un tercer país seguro, de acuerdo con lo establecido en la Directiva de Procedimiento.

En tercer lugar, la noción de tercer país seguro europeo es probablemente el concepto con una mayor falta de concreción, ya que la directiva resulta un tanto indeterminada a este respecto. Si bien, cabe entender que son aquellos Estados europeos, no miembros de la UE, que han ratificado y cumplen en la práctica las disposiciones de la Convención de Ginebra de 1951 y su Protocolo adicional de 1967, el CEDH y también cuentan con un procedimiento de asilo prescrito por la ley (Moreno-Lax, 2015: 677). Por tanto, la directiva parece exigir unos requisitos para determinar que un tercer país es seguro, que no se requieren para decidir que un tercer país europeo es seguro. En este último caso, cuando el solicitante esté intentando entrar o lo haya logrado a través de un tercer país seguro europeo, el Estado miembro podrá establecer que no se realice el examen de su solicitud de protección internacional y de la seguridad del solicitante en sus circunstancias particulares, o bien que este examen no se realice completamente (art. 39).

La aplicación de los preceptos de la directiva que se acaban de citar ha dado lugar a escasa jurisprudencia del TJUE. Únicamente se ha referido a estos preceptos para interpretar o dar contenido a cuestiones de procedimiento en el contexto del traslado de solicitantes de asilo desde el territorio de un Estado miembro a terceros Estados considerados seguros. Por un lado, en Alheto el TJUE mantiene la obligación para los Estados miembros que apliquen el concepto de tercer país seguro de cerciorarse, antes de adoptar una decisión, de que el solicitante ha tenido la oportunidad de expresar su punto de vista sobre la inadmisión de su solicitud ${ }^{8}$. Por otro lado, en Mirza se aborda el caso de la normativa húngara que establece una presunción de inadmisibilidad de las solicitudes de protección internacional presentadas por solicitantes llegados a territorio húngaro desde Serbia, considerado tercer país seguro por dicha normativa, y que no hayan presentado una solicitud de protección internacional en ese tercer país. Entre otras cuestiones, el TJUE sostiene la posibilidad de que un Estado miembro pueda trasladar a un solicitante de asilo a un tercer país seguro después de haber reconocido ser responsable del

8 Sentencia del Tribunal de Justicia de 25 de julio de 2018, Serin Alheto, 585/16, EU:C:2018:584, apdo. 124. 
examen de su solicitud de conformidad con el Reglamento Dublín, siempre que no haya adoptado una decisión sobre el fondo acerca de la solicitud de protección internacional ${ }^{9}$.

Recientemente, el TJUE ha interpretado la Directiva de Procedimiento, entre otras normas aplicables al caso, en relación con la expulsión de demandantes de protección internacional en Hungría. En concreto, examina el motivo de inadmisibilidad establecido en la legislación húngara utilizado para justificar el rechazo de las solicitudes de asilo. Esta legislación permite tal rechazo cuando el solicitante ha llegado a Hungría a través de un país clasificado como un "país de tránsito seguro" en el que no está expuesto a la persecución o al riesgo de daños graves. En este sentido, el TJUE declara que tal motivo es contrario al art. 33 de la Directiva de Procedimiento. Por tanto, los solicitantes podrán presentar una nueva solicitud de protección internacional que se clasificará como una «solicitud posterior». Aunque el art. 33.2, letra d), de esta directiva establece que una solicitud posterior, que no aporte elementos nuevos, puede considerarse inadmisible, el hecho de que el TJUE haya dictado un fallo en el que determine que un motivo de inadmisibilidad en la legislación nacional es contrario a la UE, como en este caso sucede con la legislación húngara, debe considerarse como un elemento nuevo relacionado con el examen de la solicitud de protección internacional, de conformidad con el art. 33.2, letra d), de la Directiva de Procedimiento ${ }^{10}$.

En suma, la Directiva de Procedimiento, adoptada como es obvio en el marco del sistema institucional de la $\mathrm{UE}^{11}$, es una norma de mínimos que contiene conceptos jurídicos indeterminados, como la noción de país seguro europeo. Esta norma concede bastante discrecionalidad a los Estados

9 Sentencia del Tribunal de Justicia de 17 de marzo de 2016, Shiraz Baig Mirza, 695/15 PPU, EU:C:2016:188, apdo. 53.

10 Sentencia del Tribunal de Justicia de 14 de mayo de 2020, Országos Idegenrendeszeti Főigazgatóság Dél-alföldi Regionális Igazgatóság, 924/19 PPU, EU:C:2020:367.

11 Cabe señalar a este respecto que el Parlamento Europeo planteó en 2008 un recurso de anulación contra algunas disposiciones de la Directiva de Procedimiento —en aquel momento, la Directiva 2005/85/CE_. En esencia, la cuestión que se planteó al Tribunal es si el Consejo podía legalmente establecer, en la directiva, la adopción y la modificación de las listas de países seguros por mayoría cualificada, a propuesta de la Comisión y previa consulta al Parlamento; o si, por el contrario, tal y como defendió el Parlamento, se debía aplicar el procedimiento de codecisión. El TJ constató que el procedimiento de codecisión es aplicable tanto para la adopción y la modificación de las listas de países seguros por la vía legislativa como para ejercer las competencias de ejecución en este ámbito: Sentencia del Tribunal de Justicia de 6 de mayo de 2008, Parlamento/Consejo, 133/06, EU:C:2008:257. 
miembros en aspectos relevantes como, por ejemplo, las garantías mínimas que deben prever los procedimientos acelerados, en aplicación del concepto de país de origen seguro, lo que puede menoscabar las garantías procesales del extranjero.

\section{LA APLICACIÓN DE LA NOCIÓN DE PAÍS SEGURO EN LA UNIÓN EUROPEA}

\section{LA PRÁCTICA CONVENCIONAL}

En las últimas décadas la UE ha suscrito un buen número de acuerdos de readmisión con terceros países. La Comisión mantiene que estos acuerdos proporcionan un marco estructurado de cooperación al establecer procedimientos rápidos y eficaces para identificar y retornar a extranjeros, nacionales de una de las partes, que residen de forma ilegal en el territorio de la otra parte ${ }^{12}$. Como se ha señalado, «los acuerdos de readmisión no sólo disponen el retorno de los inmigrantes en situación irregular sino también de los solicitantes de asilo cuya solicitud de protección ha sido rechazada o aquellos cuya demanda no ha sido analizada en cuanto al fondo debido a su procedencia de un tercer país considerado "seguro"» (Arenas Hidalgo, 2010: 57). Hasta la fecha, la UE ha firmado acuerdos de readmisión con Albania, Armenia, Azerbaiyán, Bosnia y Herzegovina, Cabo Verde, Georgia, Hong Kong, Macao, Moldavia, Montenegro, la Antigua República Yugoslava de Macedonia, Pakistán, Rusia, Serbia, Sri Lanka, Turquía, Ucrania y, en diciembre de 2019, con Bielorrusia.

Según la Comisión estos acuerdos permiten la rápida tramitación de las medidas de expulsión de los nacionales de estos terceros Estados, así como de nacionales de otros países. En cualquier caso, la aplicación de estos acuerdos debe respetar la Convención de Ginebra de 1951, el Protocolo de 1967 sobre el estatuto de los refugiados, los tratados internacionales relativos a la extradición, el tránsito, la readmisión de los nacionales extranjeros y el asilo —en concreto el Reglamento Dublín III-, así como el CEDH. Estos instrumentos garantizan que ninguna persona pueda ser expulsada de un Estado miembro si ello vulnera el principio de no devolución. Si la aplicación del acuerdo de readmisión contraviene los compromisos asumidos por los Estados miembros

12 Véase la información proporcionada en la web de la UE acerca de los acuerdos de readmisión en la que se explica el objetivo, puntos clave y los acuerdos de readmisión suscritos hasta la fecha por la UE: https://bit.ly/3eocqwD (las páginas web citadas a lo largo de este trabajo han sido consultadas por última vez el 25 de mayo de 2020). 
con los citados instrumentos internacionales no puede iniciarse el proceso de readmisión. Así se contempla en las denominadas cláusulas de compatibilidad que contienen los acuerdos de readmisión, y que vienen a confirmar la aplicabilidad y el respeto de los instrumentos de derechos humanos ${ }^{13}$.

En relación con Turquía, se trata de un país que ha sido y sigue siendo fuente de grandes flujos de migración irregular hacia la UE. El acuerdo de readmisión UE-Turquía permite que Turquía readmita, sin más trámites que los previstos en el acuerdo, a todas las personas que no cumplan las condiciones de entrada, permanencia o residencia en un Estado miembro. Todo ello siempre y cuando se trate de nacionales turcos, así como de nacionales de terceros países o apátridas, de conformidad con lo establecido en el art. 4 de dicho acuerdo; como, por ejemplo, aquellos que hayan entrado ilegal y directamente en el territorio de los Estados miembros tras haber permanecido en el territorio de Turquía o transitado por él (art. 4.1. letra c) ${ }^{14}$. Como es sabido, a raíz de la controvertida Declaración UE-Turquía de 18 de marzo de 2016, la UE dirigió sus esfuerzos a la efectiva implementación del acuerdo de readmisión con Turquía, con el fin de atajar la inmigración irregular proveniente de Turquía a la UE a través de Grecia. De hecho, el número de llegadas irregulares se redujo aproximadamente en un $97 \%$ desde su aplicación en comparación con el periodo anterior a la puesta en marcha de la declaración ${ }^{15}$.

Pero se puede poner en duda que Turquía cumpla los criterios exigidos por la Directiva de Procedimiento, en concreto el referido a la prohibición de torturas, tratos crueles, inhumanos o degradantes que exige el art. 38.1, d) y que, por tanto, pueda ser considerado un tercer país seguro para los solicitantes de protección internacional. De hecho, se ha constatado que las condiciones de vida de los solicitantes de asilo sirios en Turquía son inhumanas o, al menos, degradantes. En enero de 2016, el Comité para la Eliminación de la Discriminación Racial de la ONU expresó su preocupación por las malas condiciones de vida de los refugiados sirios en Turquía, así como por las deficiencias generales

13 Comunicación de la Comisión al Parlamento Europeo y al Consejo. Evaluación de los acuerdos de readmisión de la UE. Bruselas, 23 de febrero de 2011, COM(2011) 76 final, pp. 11 y 12.

14 Decisión de Consejo de 14 de abril de 2014 relativa a la celebración del Acuerdo entre la Unión Europea y la República de Turquía sobre readmisión de residentes ilegales (2014/252/UE) (DO L 134/1, de 7 de mayo de 2014). Según el acuerdo, para proceder al traslado, el art. 7.2 requiere la representación de una solicitud de readmisión a la autoridad competente del Estado requerido.

15 Comisión Europea. A Europe that protects our borders and delivers on a comprehensive migration policy. May 2019. Disponible en: https://bit.ly/2YXNRQL. 
en las condiciones económicas y sociales de migrantes y solicitantes de asilo y refugiados ${ }^{16}$.

Además, en relación con Turquía, el TEDH ha concluido la vulneración del art. 3 del CEDH en varios casos, debido a las condiciones materiales de detención de los campos de refugiados, en particular, a causa del hacinamiento y las condiciones antihigiénicas de estos lugares ${ }^{17}$. Además, este país también vulnera el principio de non refoulement prohibido por el art. 3 del CEDH al expulsar a solicitantes de asilo sirios a Siria (Fernández Arribas, 2019: 204). Todo ello pone muy en duda que Turquía sea un tercer país seguro, de conformidad con el art. 38 de la Directiva de Procedimiento, así como que pueda ser considerado como tal a la luz de la jurisprudencia del TEDH, como se comprobará en las siguientes páginas.

\section{LA PROPUESTA DE LA COMISIÓN EUROPEA POR LA QUE ESTABLECE UNA LISTA COMÚN EUROPEA DE PAÍSES DE ORIGEN SEGUROS}

En 2015 la Comisión, con el expreso objetivo de «facilitar la expedita tramitación de las solicitudes de asilo de las personas originarias de países designados seguros», presenta una propuesta de reglamento por el que se establece una lista común a la UE de países de origen seguro, a partir de los criterios comunes fijados en la Directiva de Procedimiento. Como se acaba de explicar, tales criterios son la ausencia de persecución, tortura o tratos o penas inhumanos o degradantes, ni amenaza de violencia indiscriminada en situaciones de conflicto armado internacional o interno (II). Los Estados que, inicialmente, se incluyen en la lista elaborada por la Comisión son: Albania, Bosnia-Herzegovina, Antigua República Yugoslava de Macedonia, Kosovo, Montenegro, Serbia y Turquía $[\text { sic }]^{18}$.

16 Comité para la Eliminación de la Discriminación Racial, Observaciones finales sobre los informes periódicos cuarto a sexto combinados de Turquía, 11 enero 2016, UN Doc. CERD/C/TUR/CO/4-6, párrs. 33 y 35.

17 Véanse los informes presentados por diversas instituciones de derechos humanos acerca de las condiciones materiales reinantes en los campos de refugiados, las declaraciones del propio Tribunal Constitucional de Turquía en este sentido, así como los casos en los que el TEDH ha mantenido la vulneración por parte de Turquía por este motivo en: Sentencia del TEDH de 17 de octubre de 2019, G.B. and others v. Turkey, CE:ECHR:2019:1017JUD000463315, párr. 99 a 113.

18 Anexo de la Propuesta de Reglamento del Parlamento Europeo y del Consejo por el que se establece una lista común a la UE de países de origen seguros a efectos de la Directiva 2013/32/UE del Parlamento Europeo y del Consejo, sobre procedimientos comunes para la concesión o la retirada de la protección internacional, y por el que se 
Con esta propuesta la Comisión trata de corregir algunas de las divergencias existentes entre las listas nacionales de países de origen seguros de los Estados miembros de la $\mathrm{UE}^{19}$. Si bien, el establecimiento de una lista europea de Estados seguros no impide que los Estados miembros puedan establecer sus propias listas nacionales. Por lo que no se resuelve el problema relativo a la falta de heterogeneidad con respecto a la presunción de seguridad que aplican los diferentes Estados miembros a la hora de configurar sus listas nacionales.

La Comisión propone incluir a estos Estados a partir de una evaluación general de su ordenamiento jurídico nacional en materia de protección de los derechos humanos. Para ello, se basa en datos estadísticos sobre la tasa de éxito de las solicitudes de refugio presentadas en estos Estados, la información presentada por la EASO, ACNUR y el Consejo de Europa ${ }^{20}$. Cabe destacar la aparente incoherencia de la propuesta de la Comisión, ya que aplica como indicador para catalogar a un Estado como seguro el hecho de que haya ratificado los principales tratados internacionales en materia de derechos humanos y, sin embargo, incluye en su propuesta de lista a Kosovo, Estado que no ha ratificado el CEDH. En relación con Turquía, ya se ha puesto de manifiesto su dudoso encaje tanto en la noción de país de origen seguro, a tenor del art. 36, como en el concepto de tercer país seguro, según el art. 38, los dos de la Directiva de Procedimiento (III.1). Además, cabe destacar que Turquía es el Estado que más ha infringido el CEDH, con un total de 3.224 casos en los que el TEDH ha fallado al menos la vulneración de un derecho entre 1959 y $2019^{21}$. Por otro lado, son varios los Estados miembros que advierten a sus nacionales sobre el riesgo regular y persistente de ataque terrorista en Turquía, por lo que recomiendan extremar las precauciones en caso de viaje $^{22}$. Esto explica que prácticamente ningún Estado miembro contemple a Turquía como tercer país seguro en sus listas nacionales (IV).

modifica la Directiva 2013/32/UE. Bruselas, 9 de septiembre de 2015. COM(2015) 452 final.

19 Comunicación de la Comisión al Parlamento Europeo y al Consejo. Hacia una reforma del Sistema Europeo Común de Asilo y una mejora de las vías legales a Europa. $\operatorname{COM}(2016) 197$ final. Bruselas, 6 de abril de 2016, p. 10. Véase asimismo el punto 3.2 de la Propuesta de la Comisión por la que se establece una lista común a la UE de países de origen seguros.

20 Véanse más en detalle los datos en los que se basó la Comisión para catalogar a estos Estados como países de origen seguros: Doc. COM(2015) 452 final, pp. 3 a 7.

21 TEDH, «Violations by Article and by State». Disponible en: https://bit.ly/2V5bCVR.

22 Véanse las recomendaciones de viaje del Ministerio de Asuntos Exteriores de España: https://bit.ly/2Csa0PA; del Ministerio de Asuntos Exteriores de Francia: https://bit. ly/2V00hX2; y del Ministerio de Asuntos Exteriores de Italia: https://bit.ly/3eoCrfa. 
Por su parte, uno de los datos que la Comisión toma como referencia para considerar un país como seguro es la tasa de reconocimiento de las solicitudes de asilo. En este sentido, algunos estudios han evidenciado que las tasas de reconocimiento de los países incluidos por la Comisión en su lista, como Albania y Turquía, revelan una preocupante discordancia entre las presunciones generales de seguridad y las necesidades de protección que han sido identificadas en la práctica para los nacionales que son expulsados a estos países (AIDA, 2015a: 20).

En su dictamen, el Comité Económico y Social de la UE, aunque con carácter general valora positivamente la propuesta de la Comisión, considera que puede resultar un tanto precipitado elaborar una lista cerrada de países de origen considerados seguros a los efectos previstos ${ }^{23}$. Como acertadamente mantiene el ponente del Comité Económico y Social Europeo:

La propuesta de la Comisión para la inclusión de esos siete países en la lista de Países de Origen Seguros debería hacer referencia a otros indicadores que son útiles y efectivos para medir el grado de aplicación del Derecho, y el cumplimiento de los derechos humanos, como las fuentes de información que el TEDH ha considerado relevante en su reiterada jurisprudencia, para la valoración de la situación de país de origen y el riesgo en caso de retorno ${ }^{24}$.

En este sentido no es de extrañar que el pasado junio de 2019, la Comisión retirara la propuesta de reglamento ${ }^{25}$. Como se va a poner de manifiesto a continuación, la jurisprudencia del TEDH que interpreta y aplica el art. 2 y sobre todo el art. 3 del CEDH en relación con la expulsión de solicitantes de asilo exige a las autoridades nacionales de los Estados parte que lleven a cabo un examen exhaustivo de las condiciones reinantes en el tercer Estado en cuestión y, en particular, la accesibilidad y confianza de su sistema de asilo, antes de proceder al traslado de un solicitante de protección

23 Dictamen del Comité Económico y Social Europeo sobre la Propuesta de Reglamento del Parlamento Europeo y del Consejo por el que se establece una lista común a la UE de países de origen seguros a efectos de la Directiva 2013/32/UE del Parlamento Europeo y del Consejo, sobre procedimientos comunes para la concesión o la retirada de la protección internacional, y por el que se modifica la Directiva 2013/32/UE COM (2015) 452 final. (2016/C 071/13). Ponente: José Antonio Moreno Díaz. Bruselas, 10 de diciembre de 2015 (DO C 71/82, de 24 de febrero de 2016), párr. 1.3.

24 Dictamen del Comité Económico y Social Europeo, op. cit., párr. 4.6.

25 Retirada de propuestas de la Comisión. 2019/C 210/07 (DO C 210/13, de 21 de junio de 2019). 
internacional ${ }^{26}$. Además, el TEDH ha desarrollado una serie de principios en su jurisprudencia con respecto a la evaluación del riesgo en el país de origen del solicitante de asilo que, como el propio Tribunal mantiene: "Also apply, mutatis mutandis, to the national authorities' examination of the question whether a third country from which the asylum seeker came is 'safe' ${ }^{27}$.

\section{LA PRÁCTICA DE LOS ESTADOS MIEMBROS DE LA UNIÓN EUROPEA RELACIONADA CON LA NOCIÓN DE PAÍS SEGURO}

Como se ha señalado en el epígrafe II, el art. 37 de la Directiva de Procedimiento permite a los Estados miembros establecer en su legislación interna listas nacionales de países de origen seguros a los efectos de examinar las solicitudes de protección internacional. En este sentido, varios Estados miembros de la UE han adoptado tales listas en su legislación interna, como Austria, Bélgica, Bulgaria, República Checa, Dinamarca, Francia, Alemania, Irlanda, Luxemburgo, Malta, Eslovaquia ${ }^{28}$, Hungría (AIDA, 2015a: 68), Eslovenia (EASO, 2016: 102), Estonia y Países Bajos (EASO, 2017: 141). Los principales países de origen seguros para los Estados miembros, ya sea porque se incluyen en las listas nacionales, o bien porque así lo determina la práctica legislativa y judicial de los Estados miembros, son: Albania, Bosnia-Herzegovina, Antigua República Yugoslava de Macedonia, Kosovo, Montenegro, Serbia, Georgia, Moldavia, Bangladés, India, Pakistán, Mongolia, Senegal, Ghana, Nigeria, Benin, Gabon, Botsuana, Kenya, Chile, Uruguay, Jamaica e Ucrania (AIDA, 2015a: 78).

Los últimos Estados miembros que han adoptado listas de países de origen seguros son Italia y Grecia. Por un lado, el 4 de octubre de 2019 el Gobierno italiano firma un decreto que establece una lista de trece países seguros: Argelia, Marruecos, Túnez, Albania, Bosnia-Herzegovina, Kosovo, Macedonia del Norte, Montenegro, Serbia, Ucrania, Ghana, Senegal y Cabo Verde $^{29}$. Por otro lado, el 4 de enero de 2020 el Gobierno griego adopta una Decisión Ministerial Conjunta que declara a doce países como países de

26 M.S.S. v. Belgium and Greece, cit., párrs. 365 a 368; Sentencia del TEDH de 21 de noviembrede2019, Ilias and Ahmed.v. Hungary, CE:ECHR:2019:1121JUD004728715, párr. 139 a 140.

27 Ilias and Ahmed. v. Hungary, cit., párr. 140.

28 Véanse los Estados que componen las listas de estos Estados en: https://bit.ly/2YkXNEU.

29 Decreto 4 ottobre 2019 Individuazione dei Paesi di origine sicuri, ai sensi dell'articolo 2-bis del decreto legislativo 28 gennaio 2008, $n$. 25. Disponible en: https://bit.ly/2V7IBZM. 
origen seguros: Albania, Argelia, Armenia, Gambia, Georgia, Ghana, India, Marruecos, Senegal, Togo, Túnez y Ucrania ${ }^{30}$.

Los listados de países seguros de los Estados miembros son muy heterogéneos. Esto obedece, principalmente, a dos motivos: por un lado, los Estados miembros interpretan de manera diferente los criterios establecidos en la Directiva de Procedimiento para aplicar la noción de tercer país seguro. Por otro lado, los criterios establecidos en esta directiva no son exhaustivos; por tanto, los Estados miembros pueden añadir sus propios criterios nacionales. Según el Parlamento Europeo, el modo en el que los Estados miembros valoran la seguridad en relación con los países de origen está lejos de ser homogéneo en la práctica, motivo por el que no hay un país que esté en la lista de todos los Estados miembros ${ }^{31}$.

Existen algunos Estados miembros que no adoptan listas de países de origen a los que consideran seguros a efectos de tramitar las solicitudes de asilo. Si bien, al mismo tiempo realizan un uso velado de ese concepto para acelerar el procedimiento por el que se tramitan las solicitudes de asilo de nacionales de determinados países. Por ejemplo, Suecia no aplica el concepto de país de origen seguro como tal; sin embargo, trata las solicitudes de los nacionales provenientes de Albania, Bosnia-Herzegovina, Antigua República Yugoslava de Macedonia, Kosovo, Montenegro y Serbia como solicitudes manifiestamente infundadas $y$, por tanto, sujetas a un procedimiento acelerado de tres meses (AIDA, 2015a: 79).

Con carácter general, la efectividad de las garantías procesales ${ }^{32}$ depende de que exista una provisión de tiempo suficiente para que los solicitantes puedan defender su solicitud y preparar adecuadamente una apelación ante una decisión por la que se deniega la solicitud de protección internacional. Los datos aportados por la EASO en 2014 evidencian que el 89,3 \% de

30 Véase la nota de prensa publicada por Asylum Information Database (AIDA), disponible en: https://bit.ly/2YW1rUM.

31 Parlamento Europeo. Safe Countries of Origin: proposed common EU list. Research Service, Briefing EU Legislation in progress, 8 octubre 2015, p. 3. Disponible en: https://bit.ly/2YixkaM.

32 El art. 12 de la Directiva de Procedimiento establece como garantías para los solicitantes el derecho a ser informados en una lengua que comprendan de sus derechos y obligaciones durante el procedimiento; a disponer de los servicios de un intérprete; a ponerse en contacto con una organización que preste asesoramiento jurídico a los solicitantes de protección internacional; a acceder a determinada información sobre su procedimiento; a ser notificados en un plazo razonable de la resolución decisoria de su solicitud; y a ser informado del resultado de tal resolución en una lengua que comprendan. 
las solicitudes examinadas mediante un procedimiento acelerado en la UE dieron lugar a una decisión negativa (AIDA, 2015a: 80). Por ejemplo, cuando Suiza aplica el concepto de país seguro en la tramitación de solicitudes de asilo el procedimiento es de 48 horas, junto con una reducción de las condiciones materiales de recepción. Este modus operandi ha sido descrito por la EASO como el mejor resultado para disuadir a los solicitantes de los Balcanes Occidentales de buscar protección en Suiza (EASO, 2015: 34).

En este sentido, se ha criticado que la aplicación de listas de países de origen seguros como medio para acelerar la tramitación de los procedimientos de asilo es, cuanto menos, discutible. Según el Consejo Europeo sobre Refugiados y Exiliados (ECRE), la aplicación de estas listas puede ser objeto de crítica puesto que implica una mayor carga de la prueba para el solicitante, en comparación con la carga de la prueba que normalmente se aplica en los procedimientos de asilo, que suele ser compartida. Además, para refutar tal presunción, el solicitante cuenta con plazos muy cortos donde el acceso efectivo a la asistencia legal es esencial pero, en la práctica, a menudo está ausente (AIDA, 2015b: 10) 33. $^{33}$

Por lo que respecta a la práctica de España, cabe señalar que actualmente la Ley de Asilo $^{34}$ no está completamente adaptada a la Directiva de Procedimiento. Los Estados miembros tenían la obligación de trasponer la citada directiva y comunicar a la Comisión las medidas nacionales de trasposición a más tardar el 25 de julio de 2015. La falta de trasposición de la directiva dio lugar a que la Comisión iniciara un procedimiento de incumplimiento contra España (art. 258 TFUE) ${ }^{35}$. En esta línea, algunas de las deficiencias de la ley de asilo devienen de la falta de un desarrollo del reglamento de la ley que fije las condiciones para que esta sea efectiva ${ }^{36}$. La ausencia de un reglamento en este

33 El título del presente trabajo se inspira, en parte, en el título de este documento: "Safe countries of origin": A safe concept?».

34 Ley 12/2009, de 30 de octubre, reguladora del derecho de asilo y de la protección subsidiaria (BOE n. ${ }^{\circ} 253$, de 31 de octubre de 2009).

35 En septiembre de 2015, la Comisión inició el procedimiento de incumplimiento contra España (procedimiento n. ${ }^{\circ}$ 20150413) y, en primer lugar, envió una carta de emplazamiento a España y a otros dieciocho Estados miembros por no haber comunicado las medidas nacionales de trasposición plena de la Directiva 2013/32/UE; https://bit. ly/2YkdiwN. En julio de 2019 la Comisión decidió enviar un dictamen motivado a España por no transponer completamente la Directiva 2013/32/UE; https://bit. ly/3fGAnQ0. A fecha de hoy, falta por ver si finalmente la Comisión presentará un recurso ante el TJUE.

36 La disposición final tercera de la Ley 12/2009 autoriza al Gobierno a dictar en el plazo de seis meses cuantas disposiciones de carácter reglamentario exija el desarrollo de la 
sentido, además de afectar a cuestiones técnicas, como por ejemplo la indefinición del tratamiento diferenciado para personas vulnerables, también afecta a derechos fundamentales como, por ejemplo, la posibilidad de solicitar asilo directamente en embajadas, entre otras deficiencias ${ }^{37}$.

No obstante, aunque España no ha traspuesto completamente la Directiva 2013/32/UE, en su legislación interna sí se contempla la noción de tercer país seguro. En concreto, el art. 20.1, d) de la Ley de Asilo se refiere a la antigua Directiva de Procedimiento - la Directiva 2005/85/CE — y a la noción que en ella se hace de tercer país seguro como circunstancia para la no admisión de solicitudes presentadas dentro del territorio español por falta de requisitos. Esta disposición, además de exigir los mismos principios establecidos en el art. 38 de la directiva para aplicar el concepto de tercer país seguro a un Estado, también requiere para su aplicación una relación entre el solicitante y el tercer país en cuestión "por la que sería razonable que el solicitante fuera a ese país», tal y como permite el art. 38.2, letra a) de la Directiva de Procedimiento.

España no tiene una lista de terceros países de origen seguros o terceros países europeos seguros. Sin embargo, de facto, la Oficina de Asilo y Refugio del Ministerio del Interior aplica con frecuencia el concepto de tercer país seguro a los solicitantes procedentes de Marruecos y Argelia para inadmitir sus solicitudes de protección internacional ${ }^{38}$. La Audiencia Nacional suele confirmar estas decisiones y, con carácter general, ha reiterado que Marruecos y Argelia son terceros países seguros ${ }^{39}$. Esta catalogación se justifica por el

presente ley. Sin embargo, actualmente el reglamento vigente es el que desarrolla la anterior Ley de Asilo; esto es, el Real Decreto 203/1995, de 10 de febrero por el que se aprueba el Reglamento de aplicación de la ley 5/1984, de 26 de marzo, reguladora del derecho de asilo y de la condición de refugiado, modificada por la Ley 9/1994, de 19 de mayo (BOE n. ${ }^{\circ}$ 52, de 2 de marzo de 1995).

37 Aunque de forma un tanto sorprendente, la Gran Sala, en el caso N.D. N.T. v. España, en la argumentación que desarrolla para concluir la no vulneración del CEDH por parte de España, advierte que los solicitantes tenían vías legales para acceder a territorio español, como por ejemplo mediante la solicitud de protección internacional en las embajadas y consulados de Marruecos [sic]; Sentencia del TEDH de 13 de febrero de 2020, N.D. and N.T. v. España, CE:ECHR:2020:0213JUD000867515, párr. 226 a 227.

38 Como señala Gil Bazo, el caso de España es un ejemplo de cómo algunos Estados miembros abogan cada vez por la cooperación formal e informal con terceros países de la UE y solo en un pequeño porcentaje llevan a cabo transferencias a otros Estados miembros de la UE en aplicación de Reglamento Dublín (Gil Bazo, 2015: 76).

39 SAN 1441/2018, 15 de marzo de 2018, ES:AN:2018:1441. En este pronunciamiento la Audiencia Nacional se refiere a Marruecos al señalar que «esta Sección [lo] ha considerado en reiteradas sentencias un tercer país seguro». 
hecho de que ambos Estados han ratificado la Convención de Ginebra, a pesar de que en su propia jurisprudencia la Audiencia Nacional reconoce que la mera ratificación de los convenios por parte de un Estado no implica una presunción irrefutable de que dicho Estado respete tales convenios ${ }^{40}$. Además, la Audiencia Nacional ha obviado evidenciar en sus pronunciamientos el vínculo existente entre el solicitante y el tercer país para aplicar la noción de tercer país seguro, como establece el citado art. 20.1, letra b) de la Ley de Asilo.

A la luz de los informes de diversas asociaciones de derechos humanos, se puede cuestionar la seguridad de Marruecos a los efectos de expulsión. Por ejemplo, la Comisión Española de Ayuda al Refugiado ha documentado en múltiples ocasiones las situaciones de absoluta indefensión y desprotección de personas migrantes y refugiados, situación que es más evidente en el caso de los menores y las mujeres. Estos tratos incluyen episodios de traslados forzosos hacia el sur de Marruecos y expulsiones a otros países africanos ${ }^{41}$. Por tanto, se puede poner en duda el que Marruecos cumpla el principio establecido en el art. 38.1, d) para ser considerado un tercer país seguro, ya que la expulsión de personas pertenecientes a colectivos vulnerables, como son los menores, a otros países africanos puede suponer, en atención al caso concreto, una violación de la prohibición de no expulsión en caso de violación del derecho a no ser sometido a tortura ni a tratos crueles, inhumanos o degradantes. Por su parte, Amnistía Internacional ha instado en varias ocasiones al Gobierno español a suspender la cooperación con Marruecos en materia de control migratorio, hasta que este Estado respete plenamente los derechos humanos de las personas migrantes, refugiados y solicitantes de asilo. Esta organización ha registrado repetidamente estas violaciones de derechos humanos, así como los abusos policiales y las dificultades de acceder a Melilla y la imposibilidad de acceder a Ceuta por puestos fronterizos para solicitar refugio ${ }^{42}$. Estos obstáculos al derecho a solicitar asilo son contrarios al requisito establecido en el art. 38.1, letra e) que exige que, para ser considerado seguro, en el tercer país debe existir la posibilidad de solicitar el estatuto de refugiado.

40 SAN 5200/2017, de 4 de abril de 2017, ES:AN:2017:5200, FJ $3{ }^{\circ}$.

41 Véase la nota de prensa de CEAR, «CEAR alerta del peligro que correrían las personas devueltas a Marruecos», 21 de febrero de 2019. Disponible en: https://bit. ly/30ZMIe4.

42 Véase la nota de prensa de Amnistía Internacional, «Deben paralizarse las expulsiones exprés desde España a Marruecos», de 23 de agosto de 2018. Disponible en: https:// bit.ly/2NiL9zS. 
En este sentido, en una sentencia reciente el TEDH considera que la situación de los derechos humanos en Marruecos ha mejorado durante los últimos años y reconoce que el país está haciendo esfuerzos por cumplir con las normas internacionales en materia de derechos humanos. Por tanto, la situación general del país no es de tal naturaleza como para demostrar, per se, que habría una violación del $\mathrm{CEDH}$ en caso de expulsar a un extranjero a Marruecos. Sin embargo, de conformidad con la situación personal del nacional del tercer Estado, su traslado a Marruecos puede ser contrario al art. 3 del CEDH. Así sucede en $X v$. Sweden, donde, en atención a las circunstancias del demandante, en concreto los cargos de los que se le acusa en Suecia, el TEDH concluye que su expulsión a Marruecos implica una violación del art. 3 del $\mathrm{CEDH}^{43}$. Por tanto, a la luz de la jurisprudencia del TEDH, para considerar si un Estado es seguro de conformidad con el CEDH es necesario examinar tanto la situación general en materia de derechos humanos en el Estado, como las circunstancias del sujeto objeto de expulsión, como se comprobará a continuación.

\section{LA JURISPRUDENCIA DEL TEDH SOBRE LA SITUACIÓN EN EL ESTADO DE DESTINO Y LOS FACTORES RATIONE PERSONAE}

Como se ha señalado en la Introducción, la aplicación que lleven a cabo los Estados miembros de la Directiva de Procedimiento debe respetar la jurisprudencia del TEDH. Aunque el TEDH no emplea la noción de país seguro, con su jurisprudencia contribuye a perfilar esta noción al concluir si la expulsión de un extranjero respeta los derechos humanos reconocidos en el $\mathrm{CEDH}$, según son interpretados y aplicados. Para decidir si la expulsión de un extranjero es conforme con el Convenio, es necesario realizar un análisis a sensu contrario; es decir, se debe valorar en el caso concreto si la expulsión de un extranjero a un determinado Estado comporta un riesgo de vulneración de alguna de las disposiciones del CEDH.

La evaluación debe centrarse en las consecuencias previsibles que pueden conllevar la expulsión del extranjero. Esta evaluación se lleva a cabo, por un lado, a la luz de la situación general en el tercer Estado de destino (V.1) y, por otro lado, de conformidad con sus circunstancias personales (V.2) ${ }^{44}$. La

43 Sentencia del TEDH de 9 de enero de 2018, X v. Sweden, CE:ECHR:2018: 0109JUD003641716, párr. 60.

44 Sentencia del TEDH de 11 de enero de 2007, Salah Sheekh v. Netherlands, CE:ECHR:2007:0111JUD000194804, párr. 136; Sentencia del TEDH de 10 de julio de 2018, X. v. Netherlands, CE:ECHR:2018:0710JUD001431917, párr. 73. 
vulneración del art. 3 del CEDH en los casos de expulsión puede producirse tanto por la situación general de violencia en el tercer Estado de destino, como se analiza a continuación; a consecuencia de las circunstancias personales del extranjero objeto de expulsión; o debido a la combinación de ambas situaciones ${ }^{45}$.

\section{LA SITUACIÓN GENERAL DE DERECHOS HUMANOS EN EL ESTADO DE DESTINO}

El TEDH mantiene que una situación general de violencia en un tercer Estado no implica, per se, una vulneración de los arts. 2 y 3 del $\mathrm{CEDH}$ en caso de expulsión ${ }^{46}$. De hecho, en pocas ocasiones el TEDH ha concluido la vulneración del art. 3 del CEDH únicamente por este motivo. No obstante, el TEDH no descarta que un cuadro generalizado de violencia extrema en el Estado de destino, hasta el punto de que la mera presencia del extranjero en este país suponga una amenaza a su vida y/o integridad física, pueda suponer una vulneración de los arts. 2 y 3 del CEDH en caso de expulsión ${ }^{47}$. Por tanto, antes de proceder a la expulsión, el Estado implicado debe realizar una evaluación de las circunstancias imperantes en materia de derechos humanos y seguridad nacional en el tercer Estado de destino. Con este fin, el TEDH suele conceder importancia a la información contenida en informes recientes de la ONU y también de ONG, como Amnistía Internacional ${ }^{48}$. Ahora bien, dado que estas fuentes, por lo general, se limitan a describir el panorama general en materia de derechos

45 Sentencia del TEDH de 23 de octubre de 2014, Mamazhonov v. Russia, CE:ECHR:2014:1023JUD001723913, párr. 132 y 133; Sentencia del TEDH de 21 de julio de 2015, H.S. and others v. Cyprus, CE:ECHR:2015:0721JUD004175310, párr. 269; Sentencia del TEDH de 15 de octubre de 2015, J.M. and others v. Russia, CE:ECHR:2015:1015JUD004008114, párr. 108; Sentencia del TEDH de 23 de marzo de 2016, F.G. v. Sweden, CE:ECHR:2016:0323JUD004361111, párr. 116. Sentencia del TEDH de 17 de julio de 2008, NA. v. The United Kingdom, CE:ECHR:2008:0717JUD002590407, párr. 114; Sentencia del TEDH de 27 de junio de 2013, D.N.M. v. Switzerland, CE:ECHR:2013:0627JUD002837911, párr. 47.

47 Sentencia del TEDH de 28 de junio de 2011, Sufi and Elmi v. The United Kingdom, CE:ECHR:2011:0628JUD000831907, párr. 266; Sentencia del TEDH de 29 de enero de 2013, S.H.H. v. The United Kingdom, CE:ECHR:2013:0129JUD006036710, párr. 73.

48 Sentencia del TEDH de 19 de febrero de 2013, Yefimova v. Russia, CE:ECHR:2013:0219JUD003978609, párr. 195; Sentencia del TEDH de 20 de junio de 2013, Sidikovy v. Russia, CE:ECHR:2013:0620JUD007345511, párr. 134. 
humanos en un determinado Estado y/o región, si una persona alega un riesgo específico y personal en caso de expulsión a un tercer Estado, deberá demostrar mediante otras evidencias el riesgo invocado ${ }^{49}$ (V.2).

El TEDH otorga mayor importancia a los informes que analizan la situación de los derechos humanos en el Estado de destino mediante un enfoque directo de los motivos que dan lugar a los supuestos tratos contrarios al art. 3 del CEDH en un determinado caso. El análisis que lleva a cabo el TEDH del Estado tiene como objetivo determinar si es seguro en el caso concreto, de conformidad con las disposiciones del $\mathrm{CEDH}^{50}$.

Las evaluaciones que analizan la situación en el tercer Estado de destino tienen que mostrar una fotografía real de la situación de ese país en el momento en el que se va a proceder a una expulsión concreta, con el fin de demostrar la existencia o no de un riesgo real. Para ello, el TEDH ha establecido en su jurisprudencia el principio de evaluación ex nunc de las circunstancias, aplicable a los casos de expulsión. En estos supuestos, si el demandante aún no ha sido expulsado, el momento procesal oportuno para llevar a cabo la evaluación de las circunstancias se sitúa en el momento en el que la decisión de expulsión va a ser ejecutada y no cuando esta se decide. Esto es, se requiere una evaluación completa y ex nunc de la información de la que se tiene noticia con posterioridad a que las autoridades estatales adopten la decisión de expulsión ${ }^{51}$. Esta situación generalmente se plantea si, por ejemplo, la expulsión se pospone como resultado de una medida cautelar adoptada por el TEDH en aplicación de la regla 39 del Reglamento del TEDH. Si la expulsión ya se ha llevado a cabo en el momento de plantear el caso ante el TEDH, la evaluación de la existencia del riesgo debe tomar como referencia los hechos que las autoridades estatales conocieron o deberían haber conocido en el momento de la expulsión, tanto a la luz de la situación general en el Estado de destino, como al calor de las circunstancias personales del sujeto objeto de expulsión ${ }^{52}$ (V.2).

49 Sentencia del TEDH de 4 de febrero de 2005, Mamatkulov and Askarov v. Turkey, CE:ECHR:2005:0204JUD004682799, párr. 73; Sentencia del TEDH de 18 de febrero de 2010, Puzan v. Ukraine, CE:ECHR:2010:0218JUD005124308, párr. 34 y 35 .

50 Sentencia del TEDH de 11 de julio de 2000, Jabari v. Turkey, CE:ECHR: 1999:1028DEC004003598, párr. 41; Salah Sheekh v. Netherlands, cit., párr. 141.

51 X. v. Netherlands, cit., párr. 73; Sentencia del TEDH de 29 de abril de 2019, A.M. v. France, CE:ECHR:2019:0429JUD001214818, párr. 115.

52 Sentencia del TEDH de 23 de febrero de 2012, Hirsi Jamaa and others v. Italy, CE:ECHR:2012:0223JUD002776509, párr. 121; Sentencia del TEDH de 13 de diciembre de 2012, El-Masri v. The former Yugoslav Republic of Macedonia, CE:ECHR:2012:1213JUD003963009, párr. 214; Sentencia del TEDH de 12 de enero 
En suma, la jurisprudencia del TEDH impide que los Estados miembros expulsen automáticamente a extranjeros a terceros países que consideran seguros sin realizar un análisis de la situación imperante en materia de derechos humanos en el Estado de destino en el momento de la expulsión. Por ejemplo, en Ilias and Ahmed, el TEDH sostiene que Hungría vulnera el art. 3 del $\mathrm{CEDH}$ dado que las autoridades húngaras se basan únicamente en que Serbia se encuentra incluida en su lista nacional de Estados seguros, para expulsar a los demandantes a este Estado; sin atender a los informes que relatan la situación general del Estado de destino ${ }^{53}$. Con todo, en la mayoría de los casos planteados ante el TEDH, aun constatando la existencia de una situación de violencia endémica en un tercer Estado de destino, el TEDH mantiene que el demandante debe demostrar que el riesgo de expulsión proviene de algún factor de riesgo que no sea únicamente las circunstancias genéricas. Esto es, el Tribunal sostiene que, además, deben existir circunstancias personales que propician el riesgo en caso de expulsión.

\section{LOS FACTORES RATIONE PERSONAE}

El TEDH considera que la expulsión de un extranjero vulnera del art. 3 del CEDH si los malos tratos que el demandante va a sufrir en el tercer Estado de destino alcanzan un mínimo de gravedad. Si bien la valoración de ese mínimo es relativa, ya que se debe atender a todas las circunstancias del caso, lo que incluye la duración del trato ejercido contra la persona y sus efectos físicos y mentales además de, en ocasiones, la edad, sexo y estado de salud de la víctima ${ }^{54}$.

$\mathrm{El}$ art. 3 del $\mathrm{CEDH}$ es aplicable a todas las personas que se encuentran sometidas a la jurisdicción de un Estado parte. Con independencia de si es un potencial solicitante del estatuto de refugiado o incluso al margen de que decida o no solicitar esta forma de protección internacional; a diferencia

de 2016, A.W.Q. and D.H. v. Netherlands, CE:ECHR:2016:0112JUD002507706, párr. 68; Sentencia del TEDH de 5 de julio de 2016, A.M. v. Netherlands, CE:ECHR: 2016:0705JUD002909409, párr. 80; Ilias and Ahmed v. Hungary, cit., párr. 105.

53 Hungría se basa únicamente en que Serbia es parte de la Convención de Ginebra y candidato para ser miembro de la UE para considerar que se trata de un Estado seguro y pasar a formar parte de su listado nacional; Ilias and Ahmed v. Hungary, cit. párr. 110 y 124.

54 Véase, entre otras: Sentencia del TEDH de 10 de septiembre de 2015, R.H. v. Sweden, CE:ECHR:2015:0910JUD000460114, párr. 57; A.W.Q. and D.H. v. Netherlands, cit., párr. 67; Sentencia del TEDH de 13 de diciembre de 2016, Paposhvili v. Belgium, CE:ECHR:2016:1213JUD004173810, párr. 174. 
del principio de non refoulement establecido en la Convención de Ginebra, que únicamente ampara a los refugiados ${ }^{55}$. Los criterios establecidos para la concesión del estatuto de refugiado no son idénticos a los utilizados para evaluar el riesgo de trato contrario al art. 3 del CEDH en caso de expulsión. En consecuencia, el hecho de que esté pendiente la tramitación del estatuto de refugiado no constituye, en sí mismo, un obstáculo para que el TEDH examine una demanda en virtud del art. 3 del $\mathrm{CEDH}^{56}$. Como se ha señalado, «el CEDH no protege ni expresa ni exclusivamente a los refugiados de la Convención de Ginebra, sino a aquellos que podrían "refugiarse" en su art. 3" (Abrisketa Uriarte, 2017: 139).

Con carácter general, es el extranjero objeto de expulsión quien debe probar que, en caso de ser expulsado a un tercer Estado, se vería abocado a sufrir malos tratos contrarios al art. 3 del CEDH. Los demandantes sujetos a un procedimiento de expulsión son quienes están en mejor disposición de aportar pruebas que acrediten el motivo por el que, en sus circunstancias concretas, corren el riesgo de sufrir torturas, penas o tratos inhumanos o degradantes en el tercer Estado ${ }^{57}$. Si bien, un determinado grado de especulación es inherente al art. 3 del CEDH. No se trata de exigir a los interesados que aporten una prueba clara que demuestre fehacientemente el riesgo al que estarían expuestos en caso de expulsión. La acreditación documental del riesgo previsible en caso de expulsión resulta especialmente complicada cuando el extranjero es un solicitante de refugio, a mayor abundamiento si dichas pruebas deben obtenerse del país del que el demandante huye ${ }^{58}$. Por consiguiente, la falta de pruebas en estas circunstancias no puede ser un elemento que disipe automáticamente el riesgo de tratos contrarios al art. 3 en el Estado de destino.

Por su parte, en aras a evaluar el nivel de riesgo de malos tratos inherente a una determinada expulsión, es relevante el hecho de que el extranjero

55 Jabari v. Turkey, cit., párr. 38; Saadi v. Italy, cit., párr. 153; M.S.S. v. Belgium and Greece, cit., párr. 365.

56 Sentencia del TEDH de 14 de marzo de 2013, Kasymakhunov and Saybatalov v. Russia, CE:ECHR:2013:0314JUD002626105, párr. 125; Sentencia del TEDH de 10 de julio de 2014, Rakhimov v. Russia, CE:ECHR:2014:0710JUD005055213, párr. 94; L.M. and others v. Russia, cit., párr. 103.

57 Sentencia del TEDH de 17 de enero de 2012, Othman (Abu Qatada) v. The United Kingdom, CE:ECHR:2012:0117JUD000813909, párr. 212; Sentencia del TEDH de 2 de junio de 2015, Ouabour v. Belgium, CE:ECHR:2015:0602JUD002641710, párr. 65; X. v. Netherlands, cit., párr. 44.

58 Paposhvili v. Belgium, cit., párr. 186; Sentencia del TEDH de 9 de enero de 2018, X. v. Sweden, CE:ECHR:2018:0109JUD003641716, párr. 55. 
haya sido objeto de tortura o malos tratos en el tercer Estado de destino ${ }^{59}$. En cualquier caso, con independencia de que el riesgo provenga de actores estatales o no estatales, el eventual riesgo de malos tratos al que se enfrenta el extranjero en caso de expulsión debe ser real y actual. Por tanto, la existencia de malos tratos en el pasado no significa que necesariamente el riesgo de persecución siga activo en el momento de proceder a la expulsión ${ }^{60}$.

No obstante, el TEDH considera que el hecho de que un extranjero haya sufrido malos tratos en el pasado proporciona una fuerte presunción de que existe un riesgo real y futuro de trato contrario al art. 3 del CEDH en caso de expulsión. Tales suposiciones cobran fuerza si, además, el extranjero ofrece una explicación coherente y creíble de los hechos que concuerda con la información aportada por fuentes fidedignas y objetivas sobre la situación del tercer Estado en cuestión (V.1). En estos casos, corresponde al Estado que procede a la expulsión disipar las dudas sobre el riesgo alegado en caso de expulsión ${ }^{61}$.

En ocasiones la distinción entre, por una parte, la situación general en materia de seguridad y derechos humanos y, por otra parte, la situación personal del sujeto no puede apreciarse claramente. Por ejemplo, si el extranjero objeto de expulsión alega ser un miembro de un grupo sistemáticamente perseguido y expuesto a tratos contrarios al art. 3 del $\mathrm{CEDH}^{62}$. En estos casos, el TEDH no exige al solicitante que demuestre la existencia de otros factores de riesgo ya que, de lo contrario, la protección ofrecida por el art. 3 del CEDH devendría ilusoria. El riesgo se debe determinar a la luz del relato del extranjero y la situación del tercer Estado de destino en relación con el grupo de persecución al que dice pertenecer el demandante ${ }^{63}$. Por consiguiente, determinados elementos subje-

59 Sentencia del TEDH de 19 de septiembre de 2013, R.J. v. France, CE:ECHR: 2013:0919JUD001046611, párr. 42.

60 Sentencia del TEDH de 6 de diciembre 2012, D.N.W. v. Switzerland, CE:ECHR: 2012:1206JUD002994610, párr. 42 y 45. En este sentido, en el ámbito de la UE el art. 4.4. de la Directiva 2011/95/UE establece que: «El hecho de que un solicitante ya haya sufrido persecución o daños graves o recibido amenazas directas de sufrir tal persecución o tales daños constituirá un indicio serio de los fundados temores del solicitante a ser perseguido o del riesgo real de sufrir daños graves, salvo que existan razones fundadas para considerar que tal persecución o tales daños graves no se repetirán».

61 Sentencia del TEDH de 23 de agosto de 2016, J.K. and others v. Sweden, CE:ECHR:2016:0823JUD005916612, párr. 102; Sentencia del TEDH de 21 de mayo de 2019, O.O. v. Russia, CE:ECHR:2019:0521JUD003632116, párr. 43.

62 Saadi v. Italy, cit., párr. 132; NA. v. The United Kingdom, cit., párr. 116; Sentencia del TEDH de 15 de junio de 2010, S.H. v. The United Kingdom, CE:ECHR:2 010:0615JUD001995606, párr. 69 a 71.

63 Salah Sheekh v. Netherlands, cit., párr. 148. 
tivos o ratione personae, analizados de forma aislada, pueden no ser considerados motivos suficientes para afirmar la existencia de riesgo en caso de expulsión. Sin embargo, estos mismos factores pueden constituir un riesgo de trato contrario al art. 3 del CEDH si son evaluados en el contexto de la situación imperante en el tercer Estado de destino.

En este sentido, algunos de los elementos que han sido considerados como indicadores de riesgo en caso de expulsión son: los antecedentes penales, las órdenes de detención previas, la edad, el sexo, el origen, los antecedentes del presunto miembro de un grupo perseguido, la solicitud de asilo previa presentada por el extranjero, las actividades llevadas a cabo en el tercer Estado de destino, etc. ${ }^{64}$.

En estrecha relación con las actividades llevadas a cabo por el extranjero objeto de expulsión, dado el carácter absoluto del art. 3 del CEDH, el tipo de actividades llevadas a cabo o en las que hubiera participado — por ejemplo, actos terroristas o en grupos de delincuencia organizada- no pueden servir de fundamento para no aplicar el art. 3 del CEDH, si hay motivos sustanciales para creer que la expulsión del extranjero puede abocarlo a que sufra tortura, penas o tratos inhumanos o degradantes ${ }^{65}$.

\section{LAS GARANTÍAS ASOCIADAS AL CONCEPTO DE TERCER ESTADO SEGURO A EFECTOS DE EXPULSIÓN SEGÚN EL TEDH}

\section{EL RESPETO DEL ART. 3 DEL CEDH: LA PROHIBICIÓN DE NON REFOULEMENT INDIRECTO}

El TEDH mantiene que la expulsión por un Estado parte de un extranjero a un país intermedio no exonera al Estado expulsor de su responsabilidad de garantizar que el sujeto, a su vez, no va a ser expuesto a un trato contrario al art. 3 en el tercer Estado de destino ${ }^{66}$. Por tanto, es responsabilidad del Estado parte expulsor asegurarse de que el país intermedio ofrece

64 NA. v. The United Kingdom, cit., párr. 143 y 144; Sentencia del TEDH de 15 de mayo de 2012, H.N. v. Sweden, CE:ECHR:2012:0515JUD003072009, párr. 40 a 42; Sentencia del TEDH de 20 de junio de 2017, M.O. v. Switzerland, CE:ECHR:2017: 0620JUD004128216, párr. 72.

65 Sentencia del TEDH de 1 de febrero de 2018, M.A. v. France, CE:ECHR: 2018:0201JUD000937315, párr. 58 y 59; Sentencia del TEDH de 27 de marzo de 2012, Mannai v. Italy, CE:ECHR:2012:0327JUD000996110.

66 Sentencia del TEDH de 22 de septiembre de 2009, Abdolkhani and Karimnia, v. Turkey, CE:ECHR:2009:0922JUD003047108, párr. 88; Sentencia del TEDH de 11 
garantías suficientes para evitar que el extranjero en cuestión es trasladado a su país de origen o a un tercer Estado sin una evaluación de los riesgos a los que se enfrenta. Esta obligación es aún más importante cuando el país de tránsito no es un Estado parte del $\mathrm{CEDH}^{67}$. Debe demostrarse que la evaluación realizada por las autoridades del Estado parte expulsor es adecuada y está suficientemente respaldada por información proveniente de fuentes nacionales, así como de otras fuentes fiables y objetivas como, por ejemplo, otros Estados contratantes, terceros Estados, agencias de las Naciones Unidas y ONG acreditadas (V.1 $)^{68}$.

Por tanto, la aplicación del principio de no devolución que se deriva del art. 3 no se limita a obligar a los Estados parte a constatar que el Estado de destino es seguro. Además, en el marco del preceptivo análisis que el Estado expulsor debe llevar a cabo de la situación reinante en materia de seguridad y derechos humanos en el Estado de destino (V.1), debe comprobar si se trata de un Estado parte del CEDH, así como si asume las obligaciones internacionales de conformidad con el principio de non refoulement establecido en la Convención de Ginebra sobre el Estatuto de los Refugiados. De manera que, en los casos relacionados con la expulsión de un solicitante de refugio, el TEDH no examina por sí mismo las solicitudes ni verifica cómo los Estados cumplen con sus obligaciones de conformidad con la Convención de Ginebra. Su principal tarea, derivada de la interpretación y aplicación del art. 3 del $\mathrm{CEDH}$, es verificar si existen garantías efectivas que protejan al solicitante contra la devolución arbitraria, ya sea directa o indirecta, al país de origen ${ }^{69}$.

\section{EL RESPETO A LA VIDA: LA PROHIBICIÓN DE LA PENA DE MUERTE}

Con la adopción del Protocolo n. ${ }^{\circ} 6$ al CEDH en 1983 se abolió la pena de muerte en tiempos de paz, y únicamente se permite la condena a

de octubre de 2011, Auad v. Bulgaria, CE:ECHR:2011:1011JUD004639010, párr. 106.

67 M.S.S. v. Belgium and Greece, cit., párr. 286; Sentencia del TEDH de 11 de diciembre de 2018, M.A. and others v. Lithuania, CE:ECHR:2018:1211JUD005979317, párr. 104.

68 Sentencia del TEDH de 12 de enero de 2016, A.G.R. v. Netherlands, CE:ECHR: 2016:0112JUD001344208, párr. 54; Sentencia del TEDH de 12 de enero de 2016, S.S. v. Netherlands, CE:ECHR:2016:0112JUD003957506, párr. 62; K. and others v. Sweden, cit., párr. 90.

69 Sentencia del TEDH de 23 de julio de 2013, M.A. v. Cyprus, CE:ECHR:2 013:0723JUD004187210, párr. 133; Ilias and Ahmed v. Hungary, cit., párr. 113. 
la pena de muerte por actos cometidos en tiempo de guerra o de amenaza inminente de guerra ${ }^{70}$. En el año 2002 se adopta el Protocolo n. ${ }^{\circ} 13$ al CEDH con el que se prohíbe la pena de muerte en todas las circunstancias, sin posibilidad de derogación ni reserva ${ }^{71}$. En la actualidad, 44 de los 47 Estados parte del Consejo de Europa han ratificado el Protocolo n. ${ }^{\circ} 13^{72}$.

El TEDH interpreta el art. 2 del CEDH y los protocolos 6 y 13 al Convenio de forma conjunta, de manera que se prohíbe tanto la ejecución de la pena de muerte en todas las circunstancias como la expulsión de un extranjero a otro Estado si existen motivos fundados para creer que corre un riesgo real de ser sometido a la pena de muerte en el tercer Estado de destino $^{73}$. La Federación de Rusia, pese a no ser signatario del Protocolo n. ${ }^{\circ}$ 13, aplica una moratoria de facto sobre la pena capital. Para el TEDH, esta moratoria no es una excepción que permita la imposición de la pena de muerte. El Tribunal ha podido constatar que nadie ha sido condenado a la pena capital desde 1966, por lo que la prohibición de la pena de muerte se aplica plenamente en la Federación de Rusia. En consecuencia, este Estado está obligado a no expulsar a una persona a otro país en el que existan motivos fundados para creer que corre un riesgo real de ser sometido a la pena de muerte $^{74}$. Cabe recordar en este punto que el art. 38 de la Directiva de Procedimiento establece como primer criterio para considerar un tercer país como seguro que respete la vida de los solicitantes de protección internacional.

70 Protocolo n. ${ }^{\circ} 6$ al Convenio para la Protección de los Derechos Humanos y de las Libertades Fundamentales relativo a la abolición de la pena de muerte. Estrasburgo, 28 de abril de 1983 (BOE n. ${ }^{\circ}$ 92, de 17 de abril de 1985). Todos los Estados parte del Consejo de Europa han firmado el Protocolo n. ${ }^{\circ} 6$ y todos, salvo la Federación de Rusia, lo han ratificado. Véanse las firmas y ratificaciones en: https://bit.ly/2YXtHWP.

71 Protocolo n. ${ }^{\circ} 13$ al Convenio para la Protección de los Derechos Humanos y de las Libertades Fundamentales relativo a la abolición de la pena de muerte en cualquier circunstancia. Estrasburgo, 3 de mayo de 2002 (BOE n. ${ }^{\circ}$ 77, de 30 de marzo de 2010).

72 De los tres Estados restantes, Armenia lo ha firmado, pero no lo ha ratificado, mientras que ni la Federación de Rusia ni Azerbaiyán los han firmado. Véanse las firmas y ratificaciones en: https://bit.ly/3em 9 hNX.

73 Soering v. The United Kingdom, cit., párr. 111; Sentencia del TEDH de 19 de noviembre de 2009, Kaboulov v. Ukraine, CE:ECHR:2009:1119JUD004101504, párr. 99; Sentencia del TEDH de 24 de julio de 2014, Al Nashiri v. Poland, CE:ECHR:2014: 0724JUD002876111, párr. 576; Sentencia del TEDH de 31 de mayo de 2018, Al Nashiri v. Romania, CE:ECHR:2018:0531JUD003323412, párr. 726.

74 Sentencia del TEDH de 29 de octubre de 2015, A.L. (X.W.) v. Russia, CE:ECHR:2015:1029JUD004409514, párr. 63. 
La abolición de la pena de muerte en el territorio de los Estados que conforman el Consejo de Europa implica que estos no pueden llevar a cabo acuerdos cuya ejecución implique la vulneración del derecho a la vida, de conformidad con el CEDH. En Al-Saadoon and Mufdhi v. United Kingdom existen evidencias fundadas para creer que hay un riesgo real de que los demandantes, de nacionalidad iraquí, sean condenados a la pena de muerte y ejecutados en caso de regresar a Iraq. Las autoridades de Reino Unido sostienen que, en cumplimiento de un acuerdo bilateral de extradición, su única opción es enviar a los demandantes a Iraq. De conformidad con el $\mathrm{TEDH}$, un Estado parte no puede celebrar un acuerdo con otro Estado cuyo cumplimiento implique una vulneración del CEDH. El Protocolo n. ${ }^{\circ} 13$ entra en vigor para Reino Unido el 1 de febrero de 2004 y, desde ese momento, este Estado no puede celebrar ningún acuerdo internacional que implique la detención de una persona con la finalidad de enviarla a un Estado en el que va a ser sometida a un juicio mediante el que se le pueda condenar a la pena de muerte. Los Estados parte no pueden adoptar ninguna otra medida que pueda someter a personas que se encuentren bajo su jurisdicción a un riesgo real de ser condenados a muerte y ejecutados. Finalmente, en este supuesto no se demuestra que los demandantes fueran a ser sometidos a la pena de muerte en caso de regresar a su Estado de nacionalidad. Pero el TEDH evalúa que el sufrimiento psicológico inherente a la incertidumbre soportada por los demandantes ante una inminente expulsión con el riesgo de ser condenados y ejecutados supone una vulneración del art. 3 del $\mathrm{CEDH}^{75}$.

En efecto, en los supuestos en los que está en juego la expulsión de extranjeros bajo la amenaza de que les sea aplicada la pena de muerte, el TEDH valora que, con independencia de que finalmente la condena a la pena de muerte sea o no ejecutada, el sufrimiento psicológico de los sujetos ante su eventual ejecución constituye un trato inhumano contrario al art. 3 del $\mathrm{CEDH}$. En la mayoría de los casos que han sido planteados ante el TEDH en relación con el riesgo de vulneración del derecho a la vida en caso de expulsión, se ha constatado una vulneración del art. 3 del CEDH. Una vez demostrada tal vulneración, el Tribunal no considera necesario examinar si también se han violado los derechos de los demandantes en virtud del art. 2 del CEDH y el art. 1 del Protocolo n. ${ }^{\circ} 13^{76}$.

75 TEDH de 2 de marzo de 2010, Al-Saadoon and Mufdhi v. The United Kingdom, CE:ECHR:2010:0302JUD006149808, párr. 133, 144 y 145.

76 En este sentido véase: Sentencia del TEDH de 5 de septiembre de 2013, K.A.B. v. Sweden, CE:ECHR:2012:0410JUD005981908, párr. 67; L.M. and others v. 


\section{LA JURISPRUDENCIA DEL TEDH APLICADA A LOS ESTADOS MIEMBROS DE LA UE}

En su jurisprudencia, el TEDH reconoce los retos que deben afrontar los Estados europeos para gestionar la inmigración irregular, en un escenario marcado por la crisis económica, que a buen seguro se verá agudizada por la crisis sanitaria provocada por la COVID-19, y las recientes transformaciones sociales y políticas que han afectado especialmente a determinadas regiones de África y del Medio Oriente ${ }^{77}$. En particular, los Estados que forman la frontera exterior de la UE se enfrentan a dificultades importantes para gestionar los flujos crecientes de inmigrantes. Este problema se agrava por el elevado número de solicitudes de asilo presentadas en algunos Estados. Pero al mismo tiempo el TEDH mantiene con toda claridad que «los problemas relativos a la gestión de flujos migratorios no pueden servir para justificar la utilización de prácticas incompatibles con las obligaciones de un Estado en virtud del Convenio» ${ }^{78}$.

El conocido como Sistema de Dublín determina el Estado miembro responsable de una solicitud de asilo presentada por un extranjero en el territorio de uno de los Estados miembros de la UE. Según el Reglamento Dublín $^{79}$ solo un Estado miembro es responsable del examen de una solicitud de asilo. Cuando un Estado miembro reciba una solicitud de asilo y considere que el responsable del procedimiento de examen es otro Estado de la UE, debe solicitar a este último Estado que se ocupe de la solicitud. El Estado miembro designado como responsable de la solicitud de asilo debe tramitarla. El capítulo III del Reglamento Dublín contiene una jerarquía de criterios que permiten determinar el Estado miembro responsable del examen de las

Russia, cit., párr. 108; Sentencia del TEDH de 7 de diciembre de 2017, D.L. v. Austria, CE:ECHR:2017:1207JUD003499916, párr. 63; Sentencia del TEDH de 10 de octubre de 2019, O.D. v. Bulgaria, CE:ECHR:2019:1010JUD003401618, párr. 43.

77 Sentencia del TEDH de 15 de diciembre de 2016, Khlaifia and others v. Italy, CE:ECHR:2016:1215JUD001648312, párr. 241; Sentencia del TEDH de 3 de octubre de 2017, N.D. and N.T. v. España, CE:ECHR:2017:1003JUD000867515, párr. 101.

78 Hirsi Jamaa and others v. Italy, cit., párr. 179.

79 Reglamento (UE) n. ${ }^{\circ}$ 604/2013 del Parlamento Europeo y del Consejo de 26 de junio de 201 por el que se establecen los criterios y mecanismos de determinación del Estado miembro responsable del examen de una solicitud de protección internacional presentada en uno de los Estados miembros por un nacional de un tercer país o un apátrida (Texto refundido) (DO L 180/31, de 29 de junio de 2013). 
solicitudes de protección internacional presentadas por nacionales de terceros países o apátridas. Si ninguno de tales criterios es aplicable al caso concreto, existe una cláusula residual que establece que, en el supuesto de que el cruce de la frontera se haya llevado a cabo de forma irregular, el Estado miembro en el que haya entrado de tal forma será responsable del examen de la solicitud de protección internacional (art. 13). Asimismo, existe una cláusula de discrecionalidad que permite a los Estados miembros examinar una solicitud de protección internacional que le sea presentada y cuyo examen no le incumba de conformidad con el Reglamento Dublín III (art. 17).

Del tenor literal del Reglamento Dublín III se deriva una presunción de que todos los Estados miembros de la UE son seguros, ya que se permite que un Estado miembro inadmita una solicitud y traslade la responsabilidad de su tramitación al Estado miembro competente, de acuerdo con los criterios de determinación del Estado miembro responsable (capítulo III del Reglamento Dublín). Por ello, es posible el traslado automático de solicitantes de asilo entre los Estados que aplican el reglamento; estos son todos los Estados miembros de la UE, además de Noruega, Islandia, Suiza y Liechtenstein.

Sin embargo, el TEDH rechazó esta presunción en el leading case M.S.S. $v$. Belgium and Greece, en el que decidió que el traslado de un ciudadano afgano por parte de Bélgica a Grecia, en aplicación del Sistema de Dublín, constituye una violación de varias disposiciones del $\mathrm{CEDH}$, entre ellas el art. 3. El TEDH considera que, de conformidad con las circunstancias imperantes en Grecia, el traslado del demandante vulneraría el art. 3 del $\mathrm{CEDH}$ y, por tanto, no es seguro a la luz de la Directiva de Procedimiento. El Estado belga tenía la obligación de verificar antes de proceder al reenvío del demandante que los estándares de derechos humanos del sistema de recepción de inmigrantes en Grecia eran acordes con las disposiciones del CEDH. Bélgica alegó que no le correspondía tramitar la solicitud de protección internacional del demandante, según el Reglamento Dublín. Por tanto, justificó el traslado en el cumplimiento de sus obligaciones de conformidad con el Derecho de la UE. Pero el TEDH recordó, por una parte, que Bélgica podía haber hecho uso de la cláusula de discrecionalidad, y asumir la tramitación de la solicitud de asilo del demandante, cumpliendo con ello las disposiciones del CEDH y con el derecho de la UE; por otra, que los Estados parte siguen siendo responsables en virtud del CEDH de todos los actos y omisiones llevados a cabo en aplicación de otras obligaciones jurídicas como, en este caso, el SECA ${ }^{80}$.

80 M.S.S. v. Belgium and Greece, cit., párr. 161 a 195 y párr. 338. 
El caso M.S.S. v. Belgium and Greece marca un hito en la jurisprudencia del TEDH que supervisa el modo en el que los Estados parte del Consejo de Europa que, a su vez, son Estados miembros de la UE cumplen con las disposiciones del CEDH en el contexto de la aplicación del derecho de la UE; en concreto, el Sistema Dublín ${ }^{81}$. Este caso es el primero en el que el TEDH concluye una vulneración del art. 3 del Convenio por la expulsión de un extranjero a un Estado de la UE que, en ese momento y conforme a las circunstancias del caso, no era seguro.

M.S.S. no ha sido el único caso. El TEDH ha desarrollado un amplio corpus jurisprudencial que establece los criterios que los Estados miembros de la UE deben cumplir a la hora de aplicar el Sistema Dublín. Con carácter general, el TEDH mantiene que, de conformidad con el propósito y objeto del CEDH, la cooperación de los Estados parte no está exenta del cumplimiento del $\mathrm{CEDH}$ en un ámbito del derecho internacional particular en el que puedan existir implicaciones para la protección de los derechos humanos ${ }^{82}$, como es la aplicación del Reglamento Dublín III. De tal manera que al aplicar dicho reglamento los Estados deben asegurarse, por un lado, de que el procedimiento de asilo del país receptor respeta los derechos humanos; y, por otro lado, que ofrece garantías suficientes para evitar que un solicitante de asilo sea trasladado, directa o indirectamente, a su país de origen sin ninguna evaluación de los riesgos a los que se enfrenta desde la óptica del art. 3 del $\mathrm{CEDH}(\mathrm{V})^{83}$. A esa misma valoración se puede llegar a la hora de aplicar la Directiva de Procedimiento. Por tanto, como ya se ha señalado al inicio del

81 El Tribunal de Justicia de la Unión Europea no tarda en hacerse eco de la Sentencia M.S.S. v. Belgium and Greece. En N.S. mantiene que: «se opone a la aplicación de una presunción irrefutable según la cual el Estado miembro que el artículo 3, apartado 1, del Reglamento n. $343 / 2003$ designa como responsable, respeta los derechos fundamentales de la Unión»; Sentencia del Tribunal de Justicia de 21 de diciembre de 2011, N. S., 411/10, EU:C:2011:865, apdo. 105. Como se ha señalado con estos pronunciamientos los Tribunales de Estrasburgo y Luxemburgo parecen haber alcanzado una «suerte de acuerdo en cuanto a la inversión de la presunción del respeto de los derechos humanos» (Cortés Martín, 2018: 177). Sobre la prohibición de transferir a solicitantes de protección internacional a otros Estados miembros de la UE, como Grecia, Bulgaria, Hungría, Italia, Chipre y España, debido a los riesgos de tratos contrarios a los estándares europeos en materia de derechos humanos véase: (Morgades Gil, 2020:100-112).

82 Sentencia del TEDH de 6 de junio de 2013, Mohammed v. Austria (dec.), CE:ECHR:2013:0606JUD000228312, párr. 93.

83 Sentencia del TEDH de 5 de diciembre de 2013, Sharifi v. Austria, CE: ECHR:2013:1205JUD006010408, párr. 30. 
epígrafe V, los Estados miembros deben tener en cuenta la jurisprudencia del TEDH con la que se da contenido a los criterios de la Directiva de Procedimiento que permiten determinar si un país es seguro.

En primer lugar, como se ha señalado en el epígrafe V.1, la existencia del riesgo debe evaluarse principalmente con referencia a los hechos que el Estado parte conocía o debería haber conocido en el momento de la expulsión. Por ejemplo, en el citado caso M.S.S. v. Bélgica and Greece, Bélgica disponía de informes provenientes de ACNUR, el Comisionado del Consejo de Europa para los derechos humanos, ONG como Amnistía Internacional, Human Rights Watch, Pro-Asyl, que denunciaban el nivel insuficiente de protección de los derechos fundamentales de los solicitantes de asilo en Grecia. Así pues, para el TEDH las autoridades belgas conocían la situación general en Grecia y no debían esperar que el demandante asumiera toda la carga de la prueba $(\mathrm{V} .1)^{84}$.

En segundo lugar, como se ha explicado en el epígrafe VI.1, el Estado que realiza la expulsión debe tener garantías de que el Estado miembro de destino no va a expulsar al solicitante de asilo a su Estado de origen cuando en este último país el demandante corre el riesgo de sufrir tratos contrarios al art. 3 del $\mathrm{CEDH}^{85}$.

En tercer lugar, es necesaria una evaluación completa y ex nunc, ya que la situación en un país de destino puede cambiar con el transcurso del tiempo. Aunque el historial en materia de derechos humanos de un Estado es de interés, en la medida en que pueda arrojar luz sobre la situación actual y su probable evolución, son las condiciones que se dan en el momento de dictar la decisión las que son decisivas en aras a determinar si la expulsión es conforme con el Convenio ${ }^{86}$.

En cuarto lugar, las autoridades estatales deben analizar las circunstancias particulares del extranjero para verificar que, en su caso, la expulsión hacia un Estado es conforme a las disposiciones del CEDH. Por esta razón, la expulsión de varios extranjeros al mismo Estado puede suponer en determinados casos una vulneración del Convenio, mientras que en otros supuestos, a tenor de las características personales del sujeto tales como la edad, el estado de salud de

84 M.S.S. v. Belgium and Greece, cit., párr. 347 a 352.

85 Véase en este sentido: Sentencia del TEDH de 7 de marzo de 2000, T.I. v. The United Kingdom (dec.), CE:ECHR:2000:0307DEC004384498 y Sentencia del TEDH de 2 de diciembre de 2008, K.R.S. v. The United Kingdom (dec.), CE:ECHR:2008: 1202 DEC003273308.

86 Sentencia del TEDH de 3 de julio de 2014, Mohammadi v. Austria, CE:ECHR:2014: 0703JUD007193212, párr. 65, 70, 74 y 75; Sentencia del TEDH de 30 de junio de 2015, Ibragimov v. Slovakia (dec.), CE:ECHR:2015:0630DEC006591610, párr. 55. 
la víctima o la existencia de menores en el núcleo familiar, la expulsión a ese Estado puede ser segura ${ }^{87}$.

En suma, el análisis de toda esta jurisprudencia demuestra que los Estados miembros de la UE no pueden aplicar el Reglamento Dublín como si establecieran una presunción iure et de iure de que todos los Estados miembros de la UE son seguros. El automatismo en la aplicación del Sistema Dublín debe ceder ante las posibles vulneraciones de derechos humanos de los solicitantes de protección internacional en un determinado Estado miembro. Por tanto, la cláusula de discrecionalidad ya no es entendida como una herramienta discrecional, sino como una garantía para el cumplimiento del CEDH (Morgades Gil, 2012: 194-195). El hecho de que el TEDH en situaciones referidas a un mismo Estado en determinados casos haya concluido en una vulneración de $\mathrm{CEDH}$ y en otras no demuestra que la determinación del riesgo se basa en un análisis casuístico. Los Estados miembros de la UE no pueden ignorar las circunstancias reinantes en el Estado miembro de destino o dar por cumplidos los compromisos asumidos por este con los derechos fundamentales. Por lo que, para proceder al traslado de solicitantes de protección internacional de un Estado miembro de la UE a otro, de conformidad con lo dispuesto en el Reglamento Dublín, los Estados miembros no solo deben cumplir el derecho de la UE; también deben analizar los factores que determinan el riesgo de conformidad con la jurisprudencia del TEDH. En consecuencia el TEDH, a través de su jurisprudencia, monitorea el cumplimiento por los Estados miembros de la UE de sus obligaciones en materia de política europea común de asilo, siempre de conformidad con el CEDH.

\section{CONSIDERACIONES FINALES}

Con carácter general, el desarrollo del proceso de integración europea y de su ordenamiento jurídico ha contribuido a aportar una mayor seguridad jurídica en favor del respeto de los derechos humanos de los extranjeros, en el marco del derecho internacional particular que constituye la UE. En este

87 En este sentido, confróntese la Sentencia del TEDH de 13 de enero de 2015, A.M.E. v. The Netherlands (dec.), CE:ECHR:2015:0113DEC005142810, párr. 35 a 37 y la Sentencia del TEDH de 30 de junio de 2016, A.S. v. Switzerland, CE:ECHR:2015: 0630JUD003935013, párr. 35 y 36, con la Sentencia del TEDH de 4 de noviembre de 2014, Tarakhel v. Switzerland, CE:ECHR:2014:1104JUD002921712, párr. 121 a 122; la Sentencia del TEDH de 17 de mayo de 2016, S.M.H. v. Netherlands, CE:ECHR:2016:0517DEC000586813; y la Sentencia del TEDH de 28 de junio de 2016, N.A. and others v. Dinamarca, CE:ECHR:2016:0628DEC001563616. 
contexto, la Directiva de Procedimiento se configura como una norma de mínimos, cuyo objetivo es establecer procedimientos comunes a todos los Estados miembros para conceder y retirar la protección internacional; esto es, el refugio y la protección subsidiaria. En este contexto, la noción de país de origen seguro permite a los Estados miembros la tramitación acelerada de los procedimientos cuando el solicitante sea nacional de un país catalogado como seguro. Por otro lado, el concepto de tercer país seguro posibilita la inadmisión automática de una solicitud de asilo y la transferencia del solicitante a dicho tercer país donde, en teoría, podría pedir protección.

Los Estados miembros, a la hora de proceder al traslado de un extranjero a un tercer Estado en aplicación del concepto de país seguro, en cualquiera de sus tres acepciones, no solo deben atender a lo establecido en la Directiva de Procedimiento, sino que también se encuentran obligados a cumplir con las normas sobre derechos humanos establecidas en el CEDH, según estas son interpretadas y aplicadas por el TEDH. En este sentido, aunque el TEDH no es un tribunal de inmigración y asilo, sí asegura una suerte de protección indirecta a todos los solicitantes de protección internacional, si en el marco del procedimiento por el que se tramita su solicitud se vulneran algunos de los derechos consagrados en el CEDH o sus protocolos adicionales.

En relación con esta jurisprudencia, la prohibición de torturas, penas o tratos inhumanos o degradantes regulada en el art. 3 del CEDH como derecho inderogable ha permitido el desarrollo de una jurisprudencia con la que se concreta la protección que los Estados parte deben garantizar a los extranjeros objeto de expulsión. Para valorar el riesgo de expulsión el TEDH evalúa las condiciones imperantes en el Estado de destino. En este sentido, la labor de organizaciones gubernamentales y de ONG dedicadas al trabajo de campo es fundamental para tomar una fotografía real de la situación de los derechos humanos en el tercer Estado en el momento de llevar a cabo una determinada expulsión. El TEDH requiere un cuadro generalizado de violencia extrema en el Estado de destino para que, por este único motivo, se pueda impedir la expulsión. Este elevado umbral de exigencia es paliado, porque al mismo tiempo el TEDH lleva a cabo una evaluación del riesgo personal que sufre el extranjero en caso de expulsión. Por tanto, aplica un examen circunstancial pero también personal de los riesgos intrínsecos a la expulsión. Para ello analiza factores ratione personae tales como si el sujeto pertenece a una determinada minoría o si ha sido objeto de malos tratos en el pasado. En cualquier caso, el análisis de los elementos objetivos y subjetivos inherentes a la expulsión deben tener en cuenta siempre el principio de efectividad. Por ello, el eventual riesgo potencialmente asociado a una expulsión debe ser real y estar presente en el momento de llevar a cabo una expulsión determinada. 
Por otra parte, dentro de esta jurisprudencia el TEDH desarrolla y concreta una serie de garantías que van intrínsecamente asociadas a la noción de Estado seguro: por un lado, que el Estado de destino respete el principio de no devolución y, por otro lado, que sea un Estado abolicionista de la pena de muerte $\mathrm{o}$, en la práctica, no la ejecute. Respecto a la primera garantía, el TEDH ha desarrollado a partir del art. 3 el principio de non refoulement indirecto. A través de este principio el TEDH fiscaliza la situación en materia de derechos humanos en el tercer Estado al que se va a expulsar el extranjero. Por esta vía, el TEDH está exportando en buena medida la aplicación del CEDH a terceros Estados, a pesar de que estos últimos no hayan ratificado este Convenio y por tanto no sean Estados parte en este tratado internacional. De algún modo, a los terceros Estados de destino se les aplica la jurisprudencia del TEDH, ya que este Tribunal comprueba si la situación en materia de derechos humanos en estos Estados cumple los criterios jurisprudenciales exigidos para garantizar que la expulsión es conforme con las disposiciones del CEDH. Se trata, por tanto, de una aplicación extraterritorial del Convenio de Roma, de forma un tanto indirecta si se quiere, pero que sin duda está dirigida a prevenir las vulneraciones más graves de los derechos humanos reconocidas en el CEDH y, de algún modo, monitorizar el cumplimiento de los derechos humanos más allá de las fronteras de los Estados parte en este tratado internacional.

En relación con la segunda garantía, en su jurisprudencia el TEDH prohíbe la expulsión de un extranjero a un Estado en el que el extranjero corra el riesgo de ser sometido a la pena de muerte. En las pocas demandas planteadas ante el TEDH por este motivo, el Tribunal suele concluir la vulneración del art. 3 del CEDH por los sentimientos de angustia que puede experimentar el extranjero ante el riesgo de ser expulsado bajo la amenaza de ser condenado a muerte en el Estado de destino. Así pues, aunque el TEDH interpreta de forma integrada los arts. 2 y 3 del CEDH, en su práctica judicial concede una mayor relevancia a los derechos que preserva el art. 3 del CEDH, como se demuestra en Al-Saadoon and Mufdhi v. United Kingdom.

A la luz de esta jurisprudencia, el establecimiento de listas de Estados seguros, ya sean las que aplican los Estados mediante listas nacionales o las que de facto llevan a la práctica, ya sea la propuesta por la Comisión, con las consecuencias que se han explicado en los epígrafes III y IV, conlleva un riesgo intrínseco de vulneración del art. 3 del CEDH. A la vista de la jurisprudencia analizada, la valoración del riesgo de vulneración del art. 3 del $\mathrm{CEDH}$ conlleva una evaluación de las circunstancias imperantes en el Estado de destino, unido al indisociable examen de las circunstancias personales del extranjero objeto de expulsión. Evaluar la seguridad general de un país no permite que se tengan en cuenta adecuadamente las circunstancias indivi- 
duales de, por ejemplo, miembros de grupos minoritarios que pueden verse específicamente discriminados en determinados países que pueden ser seguros para el resto de la población, como puede ser el caso del colectivo LGTBI. Por tanto, la adopción de una lista de Estados seguros, hacia donde los extranjeros puedan ser expulsados mediante la tramitación acelerada de sus solicitudes de protección internacional o mediante la inadmisión de las mismas, puede traducirse en una especie de expulsión automática, que puede ser contraria a los arts. 2 y 3 del CEDH según son interpretados y aplicados por el TEDH (V, VI y VII). La jurisprudencia del TEDH ya brinda algún ejemplo, como demuestra el caso Ilias and Ahmed, de 2017 (V.1).

La protección efectiva exigida por el TEDH a la hora de garantizar los derechos humanos de los extranjeros y en particular el cumplimiento del art. 3 del CEDH exige a los Estados parte evaluar las circunstancias reinantes en el Estado de destino antes de proceder a la expulsión. Por lo que no cabe aplicar conceptos estereotipados para valorar la seguridad de un Estado. Por ello, del mismo modo que el TEDH niega que todos los Estados miembros de la UE sea seguros iure et de iure, tampoco cabe expedir un certificado de país seguro a un Estado automáticamente por el hecho de figurar en una lista y no porque la expulsión, en ese caso concreto, respeta los derechos humanos. En ningún caso se puede afirmar genéricamente que un país es seguro en todos los casos de expulsión, como hace el juez checo del TEDH, Aleš Pejchal, quien demuestra un desconocimiento supino de la jurisprudencia del Tribunal donde desempeña sus funciones al afirmar que «Morocco - which from the perspective of international law is a safe country ${ }^{88}$.

Cabe proponer el desarrollo y concreción de los criterios establecidos en la Directiva de Procedimiento para catalogar a un país como seguro, ya sea un país de origen o un tercer Estado, tomando como referencia los criterios desarrollados por el TEDH en su jurisprudencia relativa a los arts. 2 y 3 en este contexto. En este sentido, el TEDH ha desarrollado un corpus jurisprudencial

88 N.D. and N.T. v. España, CE:ECHR:2020:0213JUD000867515, concurring opinion of judge Pejchal, párr.6. En este caso el Tribunal inadmitió la queja alegada por los demandantes en relación con el art. 3 del Convenio, respecto al principio de no devolución, por lo que dicha cuestión no fue objeto de la Decisión que adopta el TEDH. No obstante, actualmente se encuentran en trámite de admisibilidad ante el TEDH dos casos relacionados con las "devoluciones en caliente», Doumbe Nnabuchi, y Balde y Abel, donde se plantea la vulneración del art. 3 del $\mathrm{CEDH}$ en relación al principio de no devolución; sin embargo, todavía no se ha dictado la decisión de admisibilidad en ninguno de los dos casos; Doumbe Nnabuchi v. España, comunicado al Gobierno español el 14 de diciembre de 2015; Balde y Abel v. España, comunicado al Gobierno español el 12 de junio de 2017. 
sobre el uso de las garantías diplomáticas como condición necesaria para proceder a la expulsión de un extranjero si existe riesgo de vulneración del art. 3 del CEDH. Las garantías diplomáticas son definidas como «el compromiso del país receptor de que la persona en cuestión sea tratada de acuerdo con las condiciones establecidas por el país remitente o, en términos más generales, de conformidad con sus obligaciones de derechos humanos según el derecho internacional» (ACNUR, 2006: 2).

La jurisprudencia del TEDH estudiada a lo largo de este trabajo y, más en particular, la jurisprudencia sobre las garantías diplomáticas ha concretado una serie de criterios interpretativos más o menos generales que permiten definir en qué medida las garantías diplomáticas eliminan o reducen el riesgo de vulneración del art. 3 del CEDH para el extranjero objeto de expulsión. En concreto, once son los criterios interpretativos que en el leading case Othman v. United Kingdom el TEDH desarrolla y estos son: 1) que los términos de las garantías hayan sido comunicados al TEDH; 2) el carácter, bien sea preciso, general y/o vago de las garantías diplomáticas; 3) el autor de las garantías y su capacidad, o no, de comprometer al Estado de acogida; 4) la probabilidad de que las autoridades locales cumplan las garantías diplomáticas cuando estas son ofrecidas por el Gobierno central del Estado de destino; 5) que el riesgo de vulneración esté previsto por el ordenamiento interno, como por ejemplo la aplicación de la pena de muerte; 6) el hecho de que procedan, o no, de un Estado contratante; 7) la duración y la fuerza de las relaciones bilaterales entre el Estado de envío y el Estado de acogida, incluida la actitud anterior del Estado de acogida frente a garantías similares; 8) la posibilidad de verificar objetivamente el cumplimiento de las garantías ofrecidas mediante mecanismos de control; 9) la existencia, o no, de un verdadero sistema de protección contra la tortura en el Estado de acogida y la voluntad de este Estado de cooperar con los mecanismos internacionales de control; 10) el hecho de que el autor haya, o no, sido maltratado en el Estado de acogida; 11) el examen o la ausencia de examen por los tribunales internos del Estado de partida de la fiabilidad de las garantías diplomáticas ${ }^{89}$.

De los once criterios que, a título no exhaustivo, el TEDH establece para evaluar el grado de seguridad de las garantías diplomáticas, algunos de ellos pueden extrapolarse y contribuir a desarrollar los criterios establecidos en la Directiva de Procedimiento para considerar un país como seguro. Estos criterios podrían ser: el carácter legal o ilegal del riesgo de vulneración del art. 3 en el Estado de destino ${ }^{90}$; si el Estado de destino es parte del CEDH; la

89 Othman v. United Kingdom, cit., párr. 189.

90 Por ejemplo, en Saoudi c. España el demandante, acusado de terrorismo, alega que, en caso de ser expulsado a Argelia, se vería abocado a la pena de muerte o a la cadena 
duración y la intensidad de las relaciones bilaterales entre el Estado que expulsa y el Estado de destino; y la posibilidad de verificar, mediante mecanismos de control, ya sean internos o internacionales, que los tratos percibidos por el extranjero en el tercer Estado de destino no contravienen el art. 3 del CEDH. De hecho, el TEDH ya ha hecho uso de los criterios establecidos en su jurisprudencia aplicable a las garantías diplomáticas para determinar si un Estado es seguro, de conformidad con el $\mathrm{CEDH}$, en el contexto del traslado de un extranjero desde un Estado miembro en aplicación del Sistema Dublín. En el citado caso Tarakhel el Tribunal de Estrasburgo condiciona el envío de un solicitante de asilo de Suiza a Italia a la previa obtención de garantías que permitan asegurar que el trato brindado por las autoridades italianas a los menores se adaptará a la edad de estos y mantendrán la unidad familiar ${ }^{91}$. El peso que debe atribuirse a los criterios establecidos en la lista propuesta dependería del caso concreto y del momento en el que se aplican. En consecuencia, deben ser valorados en el contexto en el que se emplean para que, de este modo, la aplicación de los criterios sea casuística, al igual que lo es el enfoque adoptado por el TEDH en su jurisprudencia a la hora de determinar si un Estado es seguro a los efectos del CEDH para expulsar a un extranjero.

En definitiva, la UE y sus Estados miembros deben desarrollar sus políticas de asilo de forma y modo que se garantice la aplicación del concepto de país seguro de conformidad con los valores fundamentales sobre los que se sustenta la propia Unión, como es el respeto de los derechos humanos, según establece el art. 2 del TUE. Para ello, la UE y sus Estados miembros deben respetar y aplicar la jurisprudencia de la más alta instancia judicial europea en materia de derechos humanos, cuya interpretación de las disposiciones del $\mathrm{CEDH}$ se incorpora a la UE por la vía de los principios generales del derecho -junto con los derechos fundamentales reconocidos en las tradiciones constitucionales de los Estados miembros- (art. 6 TUE). Además, la Carta de Derechos Fundamentales de la UE, que posee el mismo valor jurídico que los Tratados, recoge expresamente que los derechos reconocidos serán interpretados de acuerdo con la jurisprudencia del TEDH. En conclusión, las medidas tendentes a descongestionar la afluencia de solicitudes de asilo

perpetua debido a los delitos que allí se le imputan. El TEDH suscribe la opinión de los tribunales nacionales acerca de que las garantías ofrecidas evitan el peligro de tratos contrarios al art. 3 del CEDH. Esta valoración se basa, por un lado, en que en Argelia la cadena perpetua es conmutada por una condena de duración limitada y, por otro lado, en que la pena de muerte no puede ser aplicada al demandante conforme a las disposiciones para las que se solicita su extradición; Sentencia del TEDH de 18 de septiembre de 2006, Saoudi v. Spain (dec.), CE:ECHR:2006:0918DEC002287106.

91 Tarakhel v. Switzerland, cit., párr. 764. 
en territorio de la UE no pueden ignorar la jurisprudencia del TEDH que interpreta y aplica las disposiciones del CEDH en el contexto de los procedimientos migratorios. El respeto de esta jurisprudencia salvaguarda de forma segura los derechos humanos de los solicitantes de protección internacional.

\section{Bibliografía}

Abrisketa Uriarte, J. (2017). La dimensión externa del Derecho de la Unión Europea en materia de refugio y asilo: un examen desde la perspectiva del non-refoulement. Revista de Derecho Comunitario Europeo, 56, 119-158. Disponible en: https://doi.org/10.18042/cepc/rdce.56.04.

- (2019). El «tercer país seguro» en el sistema europeo de asilo: ¿nomen est omen? En N. Cornago, J. L. de Castro y L. Moure (eds.). Repensar la Unión Europea: Gobernanza, Seguridad, Mercado Interior y Ciudadanía (pp. 209-223). Valencia: Tirant lo Blanch.

ACNUR (2006). Nota del ACNUR sobre las garantías diplomáticas y la protección internacional de los refugiados. Ginebra: Sección de Operaciones de Protección y Asesoría Legal. División de Servicios de Protección Internacional.

AIDA (2015a). Common Asylum System at a Turning Point: Refugees Caught in Europe's Solidarity Crisis. Asylum Information Database. Disponible en: https://bit. ly/3e9g4uc.

- (2015b). "Safe countries of origin": A safe concept? Legal Briefing, 3. European Council on Refugees and Exiles. Disponible en: https://bit.ly/2UL0aP6.

Arenas Hidalgo, N. (2010). Los acuerdos europeos de readmisión de inmigrantes en situación irregular. Diez años de política europea de readmisión a debate. Cuadernos Europeos de Deusto, 43, 53-90.

Binkovitz, I. (2018). State Practice with Respect to the Safe Third Country Concept: Criteria for Determining that a State Offers Effective Protection for Asylum Seekers and Refugees. George Washington International Law Review, 50 (3), 581-612. Disponible en: https://bit.ly/30K0TUw.

Cortés Martín, J. M. (2018). Avatares del proceso de adhesión de la Unión Europea al Convenio Europeo de Derechos Humanos. Madrid: Reus.

EASO (2015). Asylum Applicants from the Western Balkans: comparative analysis of trends, push-pull factors and responses - Update. European Asylum Support Office.

- (2016). Annual Report on the situation of Asylum in the European Union 2016. European Asylum Support Office.

- (2017). Annual Report on the situation of Asylum in the European Union 2017. European Asylum Support Office.

Fernández Arribas, G. (2019). El difícil encaje de las devoluciones de refugiados a Turquía ¿y a Libia? con el principio de non refoulement desarrollado por el Tribunal Europeo de Derechos Humanos. En N. Cornago, J. L. de Castro y 
L. Moure (eds.). Repensar la Unión Europea: Gobernanza, Seguridad, Mercado Interior y Ciudadanía (pp. 198-207). Valencia: Tirant lo Blanch.

Gil Bazo, M. T. (2015). The Safe Third Country Concept in International Agreements on Refugee Protection. Netherlands Quarterly of Human Rights, 33 (1), 42-77. Disponible en: https://doi.org/10.1177/016934411503300104.

Moreno-Lax, V. (2015). The Legality of the "Safe Third Country" Notion Contested: Insights from the Law of Treaties. En G. S. Goodwin-Gill y P. Weckel (eds.). Migration and Refugee Protection in the 21st Century: Legal Aspects (pp. 665-721). Brill; Nijhoff; Boston: The Hague Academy of International Law Centre for Research.

Morgades Gil, S. (2012). TEDH - Sentencia de 21.01.2011 (Gran Sala), M.S.S. c. Bélgica y Grecia, 30696/09 - «Artículos 3 y 13 CEDH - Prohibición de tortura y penas o tratos inhumanos o degradantes - Reglamento (CE) n. ${ }^{\text {3 343/2003 }}$ de determinación del Estado responsable del examen de una solicitud de asilo (Dublín II)». El funcionamiento efectivo de la política europea de asilo ante la garantía del derecho a no sufrir tratos inhumanos o degradantes del CEDH. Revista de Derecho Comunitario Europeo, 41, 183-204.

- (2020). The "Internal" Dimension of the Safe Country Concept: the Interpretation of the Safe Third Country Concept in the Dublin System by International and Internal Courts. European Journal of Migration and Law, 22 (1), 82-113. Disponible en: https://doi.org/10.1163/15718166-12340070.

Panella, L. (2018). La giurisprudenza della Corte Europea dei Diritti dell'Uomo e quella della Corte di Giustizia dell'Unione Europea en materia di immigrazione a confronto: un contrato insanabile? Revista Ordine Internazionale e Diritti Umani, 3. Disponible en: http://www.rivistaoidu.net/sites/default/ files/2_Panella.pdf. 